Revista lus et Praxis, Año 24, № 1, 2018, pp. 757 - 800

ISSN 0717 - 2877

Universidad de Talca - Facultad de Ciencias Jurídicas y Sociales

La colusión como práctica anticompetitiva en la contratación pública. Reciente tendencia a la participación accionaria horizontal en EE.UU. y América Latina Johannes San Miguel Giralt

Trabajo recibido el 30 de mayo de 2016 y aprobado el 5 de diciembre de 2016

\title{
La colusión como práctica anticompetitiva en la contratación pública. Reciente tendencia a la participación accionaria horizontal en EE.UU. y América Latina \\ BID-RIGGING AS AN ANTICOMPETITIVE PRACTICE IN GOVERNMENT \\ PROCUREMENT. HORIZONTAL SHAREHOLDING AS A RECENT TREND \\ IN USA AND LATIN-AMERICA
}

Johannes San Miguel Giralt*

\section{RESUMEN}

El derecho de competencia y las prácticas anticompetitivas encuentran un especial vínculo con el sector público en la colusión. La más reciente tendencia relativa a esta práctica radica en la participación accionaria horizontal como condición favorable a esta práctica. Dicha tendencia ha sido reportada por varios autores, así como autoridades de control de mercado en los EE.UU.; sin embargo, sigue siendo desconocida por la academia y las instituciones de vigilancia de mercado en América Latina.

\section{ABSTRACT}

Antitrust law and anticompetitive practice find a special bond to public interest in bid-rigging. The most recent trend regarding this practice is the horizontal shareholding as a pre-condition to such practice. This trend has been reported by several authors and antitrust authorities in the US. However it remains unknown to scholars and antitrust authorities in Latin-America.

\section{PALABRAS CLAVE}

Colusión, derecho de competencia, contratación pública.

KeYWORDS

Bid-rigging, antitrust law, public procurement.

\section{Planteamiento del problema: el fenómeno colusorio}

La colusión constituye la principal forma de corrupción en las compras públicas y el efecto negativo de este fenómeno está determinado por la enorme importancia relativa de estas últimas en la economía mundial, cuyo valor anual

\footnotetext{
* Universidad de Guayaquil, Ecuador. Email: Johannes.sanm@ug.edu.ec
} 
global es aproximadamente de 2 trillones de dólares; y en el caso de América Latina y el Caribe, las compras públicas alcanzan una cuota del 10\% al 15\% del PIB regional ${ }^{1}$. Otro de los efectos negativos de la colusión contra el sector público son los costos directos, que ascienden al 20-25\% del valor del contrato público, y en determinadas circunstancias se eleva hasta el $40-50 \%{ }^{2}$.

De modo general y preliminar, puede definirse la colusión como la práctica que se caracteriza por la actividad de varios potenciales o actuales proveedoresoferentes de las instituciones del Estado, encaminada a acordar en secreto la conducta a seguir por todos, con el propósito de evitar la competencia entre sí y beneficiarse ilegítimamente de mejores condiciones de contratación con el Estado. Usualmente, la colusión es identificable por medio de determinadas manifestaciones e incluso puede preverse a partir de condiciones favorables específicas. En la actualidad se observan tendencias hacia el surgimiento y desarrollo de una nueva condición favorable aún no reportada por la mayor parte de las autoridades de competencia a nivel global, una de ellas relativa a la participación cruzada en sociedades que dominan el mercado.

A modo de introducción, se ha dicho que la colusión se inscribe en el ámbito de las prácticas anticompetitivas reprimidas por el derecho de competencia, por medio de las limitaciones a la actividad del mercado. Estas pueden ser legítimas o ilegítimas según su fuente: un acto legislativo, consagrado y ejecutado básicamente por el Estado; o, una conducta típica y antijurídica, cometida por las empresas en el mercado.

\section{Limitaciones al derecho de competencia}

Estas son las disposiciones normativas que autorizan o consagran determinados actos o conductas intrínsecamente anticompetitivas por razones de soberanía o interés público. La mayor sistematización de este tipo de limitaciones -y de todo el derecho de competencia- la encontramos en EE.UU., que dispone tres categorías o causales limitativas de la eficacia del derecho de competencia: la acción estadal y petición de inmunidad, las exenciones federales y el efecto en el comercio interestatal. La primera de ellas, relativa a la acción estadal y petición de inmunidad, constituye una limitación en razón de las atribuciones reservadas a los Estados para regular y actuar en los mercados intra-estadales disponiendo normas anticompetitivas, como pueden ser la fijación de precios, barreras de entrada, entre otras. En este sentido, la legislatura de los estados, el gobernador, las municipalidades y agencias de la administración pública estadal, gozan de inmunidad respecto del derecho de competencia, con lo cual están autorizados

1 Otros autores ubican su participación entre un 15\% y 20\%. Véase WeISHAAR (2013), p. 8.

2 En todos los casos, consultar Volosin (2015), p. 1. 
a adoptar actos normativos y decisiones con efecto anticompetitivo. El precedente que autoriza tal inmunidad lo preside Community Communications Co. v City of Boulder, 455 US 40, 50-54, 1982; Hoover v Ronwin, 466 US 558, 567-69, 1984;y, City of Columbia v Omni Outdoor Advertising, 499 US 365, 372-73, 1991; para el caso de las municipalidades, Fisher v City of Berkeley, 475 US 260, 1986. De igual forma resulta destacable la Ley Antimonopolio para Gobiernos Locales de 1984 -Local Government Antitrust Act.

La segunda limitación, relativa a las exenciones federales, alude a los actos legislativos del Congreso que eximen a determinado sector económico o industria de cumplir con la norma antimonopolio, a pesar de varios pronunciamientos de la Corte Suprema en el sentido de que tal limitación ha de ser interpretada de modo muy estricto (Group Life \& Health Ins. Co. v Royal Drug Co., 440 US 205, 231, 1979 y National Gerimedical Hosp \& Gerontology Center v Blue Cross, 452 US 378, 389, 1981). En este sentido, los autores distinguen entre exenciones explícitas e implícitas, en la cual las primeras se derivan de la letra clara del acto normativo posterior, mientras que las segundas se derivan de un acto legislativo que expresamente no establece un efecto antimonopólico, pero su eficacia depende de tales efectos (Silver v NYSE, 373 US 341, 357, 1963). Como exención explícita, califican el sector de las cooperativas agrícolas y de pesca bajo regulación del Departamento de Agricultura (Maryland \& Va. Milk Producers Association v United States, 362 US 458, 1960); los acuerdos de transmisión de eventos deportivos entre cadenas de televisión y ligas deportivas, así como la contratación de jugadores profesionales de béisbol (Flood $v$ Kuhn, 407 US 258, 1972); el sector de la prensa escrita, los acuerdos que el Presidente determine que son vitales para la defensa nacional, las acciones y proyectos de I+D+i previamente aprobados por la Administración de Pequeñas Empresas -Small Business Administration-y el sector de seguros intra-estadal, salvo que involucre actividades de boicott según la Ley McCarran-Ferguson, entre otros.

Una de las exenciones implícitas la constituye el sector del mercado financiero; en el caso Credit Suisse Securities v Billing, 551 US 264, 275, 2007, la Corte Suprema dejó establecido que el derecho antimonopolio no alcanza a los mercados financieros, pues está regulado por legislación federal especial, que establece una agencia reguladora especializada (Securities and Exchange Commission, $-S E C-$-) y por el alto riesgo de que la aplicación combinada de la legislación antimonopolio y de mercados financieros tendría efectos adversos respecto del desempeño de este sector y constituiría un conflicto para la eficacia de la legislación del mercado de valores.

Estas limitaciones también están presentes en el derecho comunitario a través de la cláusula general del artículo 101.3 del Tratado de Funcionamiento de la Unión Europea, que excluye la aplicación de la regulación antimonopolio a los acuerdos que mejoren la producción o distribución de bienes y promuevan el 
desarrollo técnico y económico. Entre estas exenciones, deben a su vez mencionarse las de tipo explícito en bloque para determinados sectores y acuerdos como la transferencia de tecnología, los acuerdos de distribución, de especialización y los de investigación y desarrollo (Reglamento 772 de 2004, Reglamento 330 de 2010, Reglamento 1217 de 2010, Reglamento 1218 de 2010, Reglamento 461 de 2010, y Reglamento 267 de 2010).

Por último, la tercera de las limitaciones, relativa al efecto en el comercio inter-estadal, exterior y el carácter no comercial, alude, en primer término, a que están exentas de la legislación federal las conductas antimonopólicas cuyos efectos están restringidos a un Estado. En este caso, se trata de una exención en desuso dado que resulta muy difícil encontrar actividades económicas restringidas únicamente al mercado relevante estadal (McLain v Real Estate Board of New Orleans, 444 US 232, 1980 y Summit Health v Pinhas, 500 US 322, 1991). En segundo término, están exentas las conductas o acuerdos antimonopólicos en el extranjero o nacionales en función de la exportación, siempre que no tengan un efecto suficiente en el comercio exterior y en los exportadores de los EE.UU. En tercer término, están exentas de la norma antimonopolio, las conductas que ocurren fuera del ámbito del comercio, es decir, que no involucre la venta de bienes, servicios o inmuebles a cambio de determinado valor; un ejemplo de esta última exención opera en el ámbito de las instituciones de caridad (Dedication \& Everlasting Love to Animals v Humane Society, 50 F. 3d 710, 9th Circ., 1995 y otros).

Las limitaciones ilegítimas se caracterizan por no ser toleradas en razón de no corresponder a un fin proclamado legítimo por la ley; la integran las prácticas restrictivas a la competencia, ejecutadas por empresas en el mercado. Estas son precisamente las conductas que la norma prohíbe y reprime, y pueden ser de tres tipos: acuerdos anticompetitivos, abuso de posición dominante y concentración económica.

La concentración económica no es objeto de análisis en la presente contribución, no obstante, es dable sostener que es un fenómeno, la mayor de las veces, nocivo para el mercado de compras públicas. En este sentido, tómese en cuenta las consideraciones al respecto para el probablemente mayor mercado de compras públicas en el mundo: el Departamento de Defensa de los EE.UU. Sobre el tema, autores como Kovacic, han expresado preocupación por eventuales procesos de consolidación en la industria de defensa en el entendido de que la distribución de fondos a mayor número de empresas con diversidad de enfoques en innovación y de fortalezas técnicas, usualmente conduce a un mayor número de soluciones tecnológicas, cuya consideración en este específico mercado supera la importancia del precio del producto $^{3}$.

3 Véase Averitt y LANDe (2007), p. 219. 
Tales preocupaciones son compartidas fundamentalmente por el propio Departamento de Defensa -DoD-, cuyo principal propósito es mantener un mercado de compras públicas que provea diversidad de opciones y cuyo corolario lo constituyó el éxito del Departamento de Justicia -DoJ- y su División Antitrust en bloquear la fusión entre Lockheed Martin y Northrop Grumman en 1998, la cual de proceder habría reducido a tres el número de proveedores en el mercado relevante de sistemas complejos de armamento (junto a Boeing y Raytheon Hughes) y a dos los proveedores en el mercado relevante de aeronaves militares de ala fija de alta gama ${ }^{4}$.

\section{Acuerdos anticompetitivos}

Los acuerdos anticompetitivos constituyen una especie de limitaciones ilegítimas a la actuación del mercado y a su vez un género de conductas restrictivas de la competencia consistente en contratos, convenios, prácticas concertadas o conscientemente paralelas que prevengan, restrinjan o distorsionen la competencia o que potencialmente provoque tales efectos. Las tesis en torno a los acuerdos anticompetitivos se desarrollan a partir de la teoría de los costos de transacción de Coase de 1937. No obstante, no todos los acuerdos entre competidores con efecto restrictivo de la competencia son reprimibles. En este sentido deben distinguirse los acuerdos anticompetitivos per se-nakedagreements-y los acuerdos que se consideran socialmente útiles -ancillaryrestraints-.

Los acuerdos que se consideran anticompetitivos son de la más diversa índole y naturaleza, incluso los celebrados entre competidores para la coordinación de acciones y política de I+D+i bajo la forma de jointventure ${ }^{5}$. Estos se clasifican según los sujetos que forman parte del mismo, el objeto o la materia sobre la que recae el acuerdo y la forma que adoptan.

\subsection{Acuerdos anticompetitivos horizontales y verticales}

De acuerdo a los sujetos, los acuerdos pueden ser horizontales o verticales ${ }^{6}$. En el primer caso, se trata de acuerdos entre empresas ubicadas en el mismo nivel de la cadena del producto o servicio, o de productos similares o sustitutos. Por su parte, los acuerdos verticales son aquellos que se suscriben entre empresas

\footnotetext{
4 Véase Averitt y Lande (2007), pp. 220-221.

5 Véase, TAPIA (2009), p. 7.

6 Hay un sector de la doctrina anglosajona que se opone a esta clasificación: Baxter y Kessler; por su parte, Lemley y Leslie consideran que la distinción es útil en razón a un criterio de eficiencia judicial. Véase, TAPIA (2009), p. 4.
} 
ubicadas en posiciones diferentes dentro de la cadena productiva, en el cual el fabricante impone el precio de venta final al distribuidor, entre otras condiciones. Este tipo de acuerdos tiene un tratamiento normativo más favorable a diferencia de los acuerdos horizontales, dado que pueden resultar funcionales a la eficiencia, la productividad y la generación de economía de escala, con el consiguiente efecto beneficioso en el consumidor final.

Los acuerdos verticales no recibieron atención de inicio por el derecho de competencia en la Unión Europea, al punto de no distinguirse respecto de los acuerdos horizontales ${ }^{7}$. A partir de los años 70, y como resultado de la influencia de las tesis de la Escuela de Chicago y de determinadas decisiones de la Corte Suprema, las instituciones europeas comienzan a otorgar mayor atención a la distinción entre acuerdos horizontales y verticales ${ }^{8}$. En este caso, la distinción cobró importancia especial, dado que la consecuencia sería el tratamiento diferenciado de ambos tipos de acuerdos: a los acuerdos horizontales se les aplica la regla per se, mientras que a los acuerdos verticales se les aplica la regla de la razón ${ }^{9}$. Esta distinción, de inicio esporádica, se convierte en una tendencia sistemática en el precedente de los EE.UU. y en la jurisprudencia europea, a partir de un movimiento reformador del derecho de competencia a finales de la década del noventa y otorgándole un tratamiento más displicente y tolerante a los acuerdos verticales respecto de los horizontales ${ }^{10}$.

\footnotetext{
7 En los casos LTM/MBU (Caso 56/65, Société Technique Miniere v Maschinenbau Ulm, 1966, ECR 337), Consten \& Grundig (Casos 56 y 58/64, Etablissements Consten SA \& Grundig-Verkaufs-Gmbh v Comisión, 1966, ECR 299) y República Italiana v Comisión (Caso 32/65, República Italiana v Comisión, 1966, ECR 407), a pesar de la opinión del Abogado General Roemer, el Tribunal de Justicia de las Comunidades Europeas -TJCE- no delineó ningún género de distinción entre acuerdos horizontales y verticales, ignorando a los últimos. Véase Lianos (2008), p. 1030.

8 Particularmente en los casos Sylvania (Continental T.V. Inc. v GTE Sylvania Inc., 433 US 36, 1977), State Oil v Kahn (522 US 3, 1997) y Leegin (Leegin Creative Leathers Products, Inc v PSKS, Inc., 127 S Ct 2705, 2007), en los cuales la Corte Suprema y demás tribunales, de diversas maneras, sostuvieron tesis similares en el sentido de que el análisis en torno a la viabilidad de los acuerdos verticales ha de ser analizada conforme a la regla de razón respecto del efecto anticompetitivo. Todos los casos, analizados por LIANOS (2008), p. 1031.

9 Véase LiANOS (2008), p. 1.031.

10 El rigor aplicado por la Comisión a los acuerdos verticales por debajo del sostenido contra los acuerdos horizontales está motivado por el fenómeno de auto-policía. Este se caracteriza por la vigilancia que establece la propia empresa asociada en el acuerdo vertical para que su contraparte no ejerza el poder de mercado, y afecte la demanda como resultado de ello. Esto no ocurre en los acuerdos horizontales, los cuales presentan una dinámica ganar-ganar para todos los asociados, pues el efecto útil del acuerdo consiste en el incremento del margen de utilidades de todos los participantes. En este último caso no existe incentivo empresarial para socavar o reprimir el ejercicio de poder de mercado por otra empresa. Véase LiAnOS (2008), p. 1032.
} 
Este tipo de acuerdos amerita un análisis pormenorizado, pues puede tratarse de un caso de concentración económica o de auténtica subordinación empresarial a un solo sujeto en el mercado ${ }^{11}$.

\subsection{Acuerdos anticompetitivos de carácter expreso, tácito o presunto}

Los acuerdos expresos reciben la denominación de cartel, y el fenómeno por el cual las empresas competidoras en un mercado relevante alcanzan acuerdos anticompetitivos de modo expreso se le denomina cartelización ${ }^{12}$. No obstante, varios autores coinciden en sostener la denominación de cartel para los acuerdos tácitos. En derecho anglosajón, los acuerdos expresos reciben el nombre de agreement, mientras los acuerdos tácitos reciben la denominación de understanding ${ }^{13}$.

Usualmente los esfuerzos conceptuales enfocan el objeto del cartel y no su forma. En este sentido, se definen como tal los acuerdos entre competidores que tienen por objeto evitar la competencia a través de la autorregulación de la producción, venta o precio ${ }^{14}$. Entre los presupuestos para determinar la existencia de un cartel deben mencionarse las barreras de entrada, cuya inexistencia elimina el carácter restrictivo del acuerdo, al admitir el ingreso de nuevos oferentes. Otro de los presupuestos es el bajo impacto relativo en el mercado de las decisiones de producción de los productores no miembros del cartel.

Los acuerdos anticompetitivos de carácter tácito se corresponden de modo más o menos exacto a la categoría de la colusión ${ }^{15}$. Se distinguen del cártel en

\footnotetext{
11 El precedente relevante en EE.UU. según el tipo de acuerdos es amplio: en materia de ventas exclusivas-exclusive dealing-, deben mencionarse los siguientes casos: US v Griffith; Standard Fashion v Magrane-Houston; Standard Oil and Standard Stations v US; FTC v Motion Picture Advertising Service; Tampa Electric v Nashville Coal y por último, US v Microsoft. En el caso de ventas atadas -tying-, los siguientes casos: Jefferson Parish Hospital v Hyde; Eastman Kodak v Image Technical Service; Illinois Tool Works v IndependentInk, Inc.; y una vez más, US v Microsoft. Para el caso europeo, consúltense la Decisión 88/138/CEE, Eurofix Bauco v Hilti; Decisión 92/163/CEE, TetraPak Il y el caso T-201/04, Microsoft v Comisión.

12 Véase TAPIA (2009), p. 6.

13 Sin negar lo expuesto, Kaplow \& Shapiro hacen referencia indistintamente a colusión y cartel. Sin declararlo expresamente, se infiere que cartel es el acuerdo en sí, mientras que la colusión es el efecto restrictivo en la competencia provocado por el cartel (cartel agreement, collusiveoutcome, collusivebehavior); en cualquier caso no hay una distinción clara.

${ }^{14}$ Lianos, apunta a un concepto de acuerdo no enfocado en la forma sino en la intención de las partes: intercambio formal o informal de comunicación de garantía u oferta + aceptación que pueda probar la existencia de una común intención entre las partes. Véase Lianos (2008), p. 1.027.

${ }^{15}$ La Ley Sherman admite un concepto amplio de colusión, incluyendo el acuerdo tácito (In Re High Fructose Corn Syrup Antitrust Litigation, 295 F.3d 651, 654, 7th Circ, 2002, juez ponente: Posner). También lo admite el Tribunal de Justica europeo: asunto Dyestuffs (ICI Ltd v Commission, case 48/69, 1972), ambos casos mencionados por KAPLOW y SHAPIRO (2007), p. 46. Motta maneja un concepto
} 
que, si bien ambos tienen naturaleza convencional, la colusión no necesariamente constituye un acuerdo formal sino que puede y de hecho reviste carácter tácito $^{16}$. Por su parte, algunas autoridades de la competencia resaltan el carácter anticipatorio a la conducta legalmente reprobable: práctica de concertación anticipada de las condiciones de actuación en el mercado, con el propósito de competir o excluir a otros competidores potenciales (Superintendencia de Industria y Comercio, Colombia, Res. No 1055, 19/1/2009).

Dentro del concepto de colusión deben mencionarse las prácticas concertadas, como acuerdo tácito entre empresas para restringir la competencia, las cuales se determinan a través de hechos concluyentes -factaconcludentia- ${ }^{17}$. La distinción entre acuerdo expreso y práctica concertada se manifestó en el caso europeo Polypropylene, 1986; ya desaparece en el caso PVC II, 1994, al establecer como relevante la distinción entre acuerdos colusorios y no-colusorios, a partir del argumento de que en muchas ocasiones aparecen mezcladas ambos tipos de prácticas, concertadas o expresas, en una misma conducta objeto de prohibición ${ }^{18}$. El caso Dyestuffs en 1972 dispuso que solo es considerable

económico de colusión asociado al efecto: situación en la que los precios acordados por las empresas son mayores que los razonables en el mercado o son cercanos a precios de monopolio. El concepto económico alude al resultado consistente con un mercado no competitivo, mientras que el concepto jurídico alude a la forma que adquiere el acuerdo. Véase LiANOS (2008), pp. 1028 y 1029.

Otros autores del área anglosajona establecen un concepto de colusión en distinción respecto de bidrigging. Por ejemplo, en el caso chino, Weishaar la declara como una modalidad de este, junto a la corrupción en las instancias públicas: "En China, por ejemplo, el bidrigging incluye no solo la colusión sino además la corrupción; el concepto es mucho más amplio que en otras jurisdicciones". Sin embargo, el mismo autor, por su parte acoge un concepto europeo análogo al de colusión en compras públicas: "[Bidrigging] es una particular forma de coordinación entre las empresas que pueden afectar el resultado de un procedimiento de venta en el cual se presenten ofertas. Por ejemplo, las empresas pueden acordar sus posturas con antelación, o decidir qué empresa presentará la oferta más baja. De modo alternativo, pueden acordar no presentar postura alguna o rotarlas según su número o valor del contrato".

Véase WeISHAAR (2013), p. 1.

16 En este sentido, la Ley Federal de Competencia Económica de México, en su artículo 9: Prácticas Monopólicas Absolutas o acuerdos colusorios, las define como contratos o acuerdos entre competidores, que tengan por objeto o efecto la fijación de precios, obligación de restricción de la oferta, distribución de mercados, "establecer o coordinar posturas en licitaciones, concursos, subastas o almonedas públicas". La ley federal mexicana establece expresamente el acuerdo entre postores ante concurso como un tipo específico de colusión, más allá del objeto, contenido o alcance del acuerdo. Véase WiTKER (2000), p. 1.

17 La distinción entre acuerdo y práctica concertada se determina a partir de la forma que adopta la conducta de las empresas involucradas. Lianos sostiene, que la distinción radica en la evidencia: el acuerdo expreso es aquel que resulta demostrable por medio de evidencia directa, mientras que las prácticas concertadas son aquellas que solo pueden probarse con evidencia circunstancial. Véase LiANOS (2008), p. 1027.

18 En este sentido, los casos NV Limburgse, 1999 y Rhone-Poulenc, 1991; continúa la clasificación conjunta de acuerdo expreso y práctica concertada en Cartonboard, 1994; British Sugar, 1999; y, 
como práctica concertada aquella que tiene por efecto un equilibrio en los precios favorable a los competidores en conjunto ${ }^{19}$. Las prácticas concertadas en el ámbito de los acuerdos verticales, han sido asociadas al menos a dos de las siguientes conductas: una aparente acción unilateral en ejecución de un acuerdo vertical pre-existente y acuerdos entre suministrador y distribuidor ${ }^{20}$.

Por último, debe hacerse alusión a los actos presuntos, que son las conductas conscientemente paralelas ${ }^{21}$, cuales son los actos unilaterales de un competidor en relación con el comportamiento de otros competidores, con lo cual no llega a ser una forma de coordinación, menos aún un acuerdo. No obstante, se tienen por acuerdos anticompetitivos que se derivan de un comportamiento del mercado que no puede ser explicado fuera de la existencia de una conducta de los competidores encaminada a la restricción de la competencia, por lo que se presume la existencia del acuerdo anticompetitivo (caso Celofán: US v DuPont \& Co). En esta categoría de práctica anticompetitiva, el derecho anglosajón reconoce la distinción entre acuerdo anticompetitivo tácito -tacitcollusion- y presunto-consciousparalelism-22.

Un ejemplo de este tipo de conductas lo constituye el caso Wood Pulp ante la Comisión Europea. La misma declaró la existencia de colusión a pesar de no haber evidencia expresa; en tal caso, se presumió la existencia de dicho acuerdo

\footnotetext{
Preinsulated Pipe Cartel, 1999. En cualquier caso, resulta elocuente por sí mismo la definición en el caso 48/69, Imperial Chemical Industries Ltd v Comisión, 1972 ECR 619, en el sentido de tener por propósito la prohibición de cierta forma de coordinación entre empeños anticompetitivos aún en actos preparatorios, sin alcanzar el nivel de un auténtico acuerdo, y durante el cual las partes involucradas en dicho empeño sustituyen la competencia con la cooperación. Véase LiANOS (2008), p. 1.051.

19 En igual sentido, el asunto Broke Group, 1993, SCJ, sosteniendo que la colusión tácita no es en sí misma ilegal. Véase TAPIA (2009), p. 48.

20 Un ejemplo lo constituye el caso Dunlop Slazenger (Caso T-43/92, Dunlop Slazenger International Ltd v Comisión, 1994 ECR II-441), consistente en la prohibición general de exportación dispuesta por la empresa a sus distribuidores, junto a una serie de medidas para garantizar la eficacia de dicha disposición: rehúse de suministro para exportaciones paralelas, manejo de precios para suprimir competitividad a las exportaciones potenciales de los distribuidores, recompra de productos exportados por canales paralelos, marcaje de productos para determinar la fuente de las importaciones paralelas, entre otras. Véase LianOS (2008), p. 1.053.

21 También denominadas Paralelismo inconsciente o casual, Paralelismo estructural, Paralelismo consciente propio, Paralelismo consciente colusorio.

22 Una de las formas que adopta este tipo de conducta es denominada "coordinación oligopolística": "Algunos mercados tienen escasas empresas de modo que tienen una influencia en los precios y las ventas y pueden y de hecho responden a las acciones de otras empresas en el mismo mercado. En tal caso, aún sin un acuerdo explícito, tales empresas pueden coordinar esfuerzos para restringir las ventas y levantar los precios. Esto se denomina coordinación oligopolística. La gran dificultad que plantea es si la coordinación puede ser condenada sin pruebas de un acuerdo, especialmente cuando las empresas oligopólicas no pueden evitar saber que sus políticas y decisiones de precios y ventas afectarán el comportamiento de otras empresas". Véase Elhauge y Geradin (2011), p. 3.
} 
por los intercambios de información y por el hecho de que el mercado relevante no era proclive a la presencia de precios paralelos. Las conductas paralelas no son restrictivas de la competencia per se ni prohibidas, no hay concertación si puede ser explicada por el mercado. En el asunto Suiker Unie, el TJCE dispuso que la conducta paralela solo alcanza rango de colusión, si la concertación constituye la única explicación plausible.

Se le reconocen dos requisitos. Uno de carácter objetivo que alude al intento por los competidores de limitar la competencia y otro que alude a la necesaria producción de un efecto restrictivo aun cuando no sea intencional. Sin embargo en antitrust law, las conductas conscientemente paralelas suponen un elemento probatorio adicional o plus factor. La necesidad de este plus factor para configurar una conducta conscientemente paralela como modalidad de colusión ha sido un criterio establecido por Theatre Enterprises Inc. v Paramount Film Distributing Corp., 346 US 537, 1954 y posteriormente confirmado en Blomkest Fertilizer, 2000, Petroleum Products (1990) y ATP (1993) ${ }^{23}$.

Uno de los principales problemas que plantean las conductas anticompetitivas es el de la prueba de las mismas, la cual dependerá del tipo de acuerdo restrictivo de la competencia, sea expreso, tácito o presunto. En los acuerdos expresos se requerirá prueba de la celebración de dicho acuerdo entre los competidores. En el segundo caso, los acuerdos tácitos, se requerirá solamente prueba de los hechos concluyentes que implican razonablemente un entendimiento entre las partes. Por último, el acuerdo presunto no requiere evidencia pues implica una virtual inversión de la carga de la prueba por medio de la cual las partes objeto de investigación o decisión han de demostrar que la conducta conscientemente paralela es explicable fuera de un hipotético acuerdo entre ellos.

Otro de los problemas lo constituye la obtención del material probatorio dado que se trata básicamente de documentación y hechos a lo interno de empresas, que guardan celosamente la confidencialidad de sus operaciones y comunicación organizacional, además de guardar una estricta cultura o espíritu de cuerpo que reprime y estigmatiza laboral y profesionalmente las conductas de filtración-leaking-o delación-whistle-blower-por parte de sus empleados y directivos ${ }^{24}$. En este sentido y tomando en cuenta lo anterior, se han desarrollado

\footnotetext{
${ }^{23}$ Sobre el tema:

"El comportamiento paralelo no puede ser considerado en sí mismo anticompetitivo si encuentra su explicación en las condiciones del mercado, el cual debe ser analizado con meticuloso detalle. Solamente si el paralelismo tiene como única explicación una concertación (esto es, si no es la clase de comportamiento que debiera esperarse en el mercado en cuestión), él puede ser usado como base para condenar".

Véanse Kovacic y Shapiro (2000), p. 10; TAPIA (2009), p. 49.

${ }^{24}$ Ramírez Duarte reconoce que la insuficiencia de material probatorio es una de las más importantes causas de las escasas decisiones sancionatorias en materia de colusión en la contratación pública en Colombia. Véase Ramírez Duarte (2012), p. 172.
} 
programas y sistemas de clemencia y delación compensada-leniencyprogramsorientadas a empresas; iniciativas originadas en EE.UU. y dada su eficacia, se ha extendido a otras jurisdicciones nacionales.

\subsection{Acuerdos anticompetitivos según el objeto}

Se trata de aquellos tratos que se clasifican según su objeto o materia sobre la cual recaen, criterio que ha sido sostenido al menos por una legislación en el área latinoamericana (art. 47, Decreto № 2.153 de 1992, Colombia). En primer lugar, los acuerdos de fijación de precios u otras condiciones de transacción: es el tipo clásico y más común, prohibido de modo expreso por la Ley Sherman Antitrust, sección 1 bajo el razonamiento de que impide que el precio sea una decisión de la empresa a partir del libre juego de la oferta y la demanda ${ }^{25}$. Su prohibición también se basa en la presunción por la cual cualquier acuerdo de este tipo necesariamente tiene un impacto negativo injustificado en la capacidad adquisitiva del consumidor, razón por la cual en EE.UU. es una conducta prohibida per $s e^{26}$.

Las formas de manifestarse este tipo de acuerdos son muy variadas. Por ejemplo, en un caso en Australia, poco antes de cerrar las posturas, la asociación gremial reúne a los postores para discutir el pago de una nueva "cuota anual", esta es realmente el precio fijado para la licitación ${ }^{27}$.

Adicionalmente, deben mencionarse los acuerdos para la determinación de condiciones de venta o comercialización discriminatoria frente a terceros y los acuerdos para la limitación (o afectación) de la producción, desarrollo o distribución. Básicamente, son prácticas verticales de imposición al distribuidor del precio de venta al público o prohibirle la venta de productos de la competencia; son entendimientos que limitan a los productores acudir a un género o surtido de ofertas, y en tal sentido son auto-restrictivos. La decisión de restricción se basa regularmente en factores de oferta-demanda, condiciones del mercado, así como la capacidad de producción y comportamiento de la competencia ${ }^{28}$. Por

\footnotetext{
${ }^{25}$ Amén de las normas de derecho estatutario, EE.UU. cuenta con importantes precedentes sobre fijación de precios: US v Trenton Potteries; Broadcast Music, Inc (BMI) v Columbia Broadcasting System (CBS); Arizona v Maricopa County Medical Society; y, Texaco Inc. v Dagher, entre otros. En el caso europeo, deben destacarse dos casos que constituyen jurisprudencia: Decisión 85/77/CEE de 10/12/1984, Uniform Eurocheques y Decisión 86/398/CEE, Polypropilene.

26 Véase Kaplow y Shapiro (2007), p. 22.

27 Véase OCDE (2015), p. 50.

28 Sobre las restricciones a las ventas como conducta colusoria, el precedente estadounidense relevante lo encabeza el caso NCAA v Board of Regents of University of Oklahoma, mientras que en el ámbito europeo sería la Decisión 84/380/CEE de 4/7/1984, SyntheticFibres.
} 
otra parte, los acuerdos para impedir a terceros el acceso a mercados o canales de comercialización, también conocidos como boycotty que puede adoptar la forma de dumping, consisten en el acuerdo entre competidores sobre un precio más bajo que el razonable en el mercado, con el objetivo de expulsar a los competidores no coludidos ${ }^{29}$; por último, los acuerdos de distribución del mercado a través de asignación de clientes o territorios buscan evitar la competencia en términos geográficos ${ }^{30}$.

De igual forma, clasifican para la asignación de cuotas de producción o suministro, los acuerdos para la distribución o limitación de fuentes de abastecimiento de insumos, los acuerdos para la aplicación de condiciones desiguales a prestaciones equivalentes; y los acuerdos de ventas subordinadas, los cuales incluyen la exigencia de subordinación de prestaciones suplementarias ajenas al contrato principal.

\section{Elementos de la colusión}

Una vez expuesto lo relativo a los acuerdos anticompetitivos, corresponde la determinación de los elementos que componen uno de ellos que resulta objeto del presente análisis: la colusión. Es en este contexto que cabe hablar del acuerdo colusorio, el cual se caracteriza por la presencia de determinados elementos. Estos son: la existencia de acuerdo, monitoreo y detección, sanción, apelación a la incorporación y barreras de entrada ${ }^{31}$. Respecto del primer elemento relativo al acuerdo, para el antitrust law lo que se requiere no es un auténtico agreement, sino que es suficiente un entendimiento entre las partes - understanding-. Esto admite la sanción de actos colusorios posteriores a su vigencia mientras que los efectos en el mercado pervivan; en ese sentido, el caso Acerinox, 2001 en la Unión Europea. Por otra parte, el entendimiento ha de incluir medios confiables de monitoreo y detección de los que incumplan el acuerdo; para ello se utilizan mecanismos como el suministro de cifras de venta, auditor de operaciones del

\footnotetext{
29 Sobre el fenómeno de precios predatorios o dumping, la consulta del precedente estadounidense y la jurisprudencia europea debe hacerse a partir de la distinción entre precios predatorios por debajo del costo y sobre el costo. En el primer caso, consúltese el caso BrookeGroup Ltd. (Liggett) v. Brown \& Williamson Tobacco Corp. en los EE.UU. y de la casuística europea: C-62/86, Akzo Chemie BV v Comisión; Decisión 2001/354/CEE de 20/3/2001, Deutsche Post AG; el caso T-340/03, France Télécom $\checkmark$ Comisión. Para el caso de los precios predatorios por encima del costo, véanse en Europa los casos T-24/93, T-25/93, T-26/93 y T-28/93, Compagnie Maritime Belge Transps SA v Comisión; el caso T-228/97, Irish Sugar PLC v Comisión y en EE.UU., el caso US v AMR Corp.

30 En EE.UU. constituye precedente sobre distribución de mercados, el caso Palmer v BRG. En Europa, debe destacarse la Decisión 91/227 de 19/12/1990, Soda-Ash-Solvay/ICl.

31 Véase Kaplow y SHAPIRO (2007), pp. 26 y 27.
} 
cartel, espionaje, etc ${ }^{32}$. Una circunstancia de fácil detección de incumplimiento del acuerdo por las autoridades es la estrategia del gatillo -triggerstrategy-: cuando una de las empresas en colusión se percata del incumplimiento del acuerdo y jala el gatillo, es decir, se retira y compite a la Cournot, observable a través de un rápido y pronunciado incremento en el precio.

De igual forma, el entendimiento ha de incluir una pena para los que incumplan o se retiren del acuerdo, así como una apelación o incentivo a la incorporación de nuevos empresarios ya establecidos en el mercado relevante ${ }^{33}$. Por último, el entendimiento ha de erigir barreras de entrada, que son obstáculos operacionales (boycott) a la incorporación de empresas fuera del acuerdo de colusión.

Sin lugar a dudas, el principal objetivo de las prácticas colusorias lo constituye la actividad de contratación pública, en razón de lo cual se impone su análisis.

\section{Compras públicas y sus modalidades}

Las compras públicas son un factor modulador de la competencia en razón del cual los Estados actúan directamente en un mercado como promotor de pequeños y medianos empresarios, y como incentivo a la mejora en tecnología y productividad en el sector privado. De este modo, el Estado actúa como principal consumidor -oligopsonio-y en algunas ocasiones como único -monopsonio-, con el objetivo de suministrar a su institucionalidad de los insumos y productos necesarios para el logro de sus fines. De tal manera, se logran propósitos como la estimulación de determinados sectores productivos asociados a pequeños empresarios, políticas de acción afirmativa y grupos en vulnerabilidad social.

\footnotetext{
32 Entre los autores que han trabajado el tema: Connor, Porter y Leslie. Véase TAPIA (2009), p. 12.

33 A pesar del contenido económico, el concepto de mercado relevante no es pacífico. Solo para ilustrar, en recientes contribuciones en Antitrust Law Journal, los profesores Kaplow y Werden han sostenido un debate en el cual el primero ataca dicha categoría, mientras el segundo la defiende. La razón más importante de la negativa de Kaplow radica en la inutilidad del concepto para determinar la cuota de poder de mercado de una empresa determinada y que incluso puede resultar contraproducente a dicho propósito.

En cualquier caso, téngase en cuenta como mercado relevante, la delimitación temporal, espacial y por producto, del mercado, con el objetivo de someterlo a análisis económico y con ello determinar la existencia de una conducta anticompetitiva. En este sentido:

"La delineación del mercado relevante especifica el ámbito geográfico y del producto en el proceso competitivo presuntamente dañado, por tanto, aclara las alegaciones anticompetitivas y facilita su evaluación. Delinear el mercado relevante es identificar, en términos de productos y lugares, el lugar de las fuerzas competitivas centrales para el caso [...] La separación de las fuerzas competitivas activas y pasivas por medio del mercado relevante es un instrumento retórico y analítico para dar orden al caos del mundo real".

Véase WERDEN (2014), p. 2.
} 
Entre las modalidades de contratación la más común es la licitación pública, la cual se caracteriza por un proceso de formación del contrato presidido por una convocatoria a presentar ofertas o invitación en igualdad de oportunidades y un procedimiento público y transparente de selección de la mejor oferta para el interés público, a partir de bases y condiciones previamente establecidas por la entidad pública licitante ${ }^{34}$. Esta modalidad tiene por finalidad asegurar la mejor asignación posible de recursos públicos destinados a la contratación. Los elementos del proceso licitatorio, según la jurisprudencia del Consejo de Estado colombiano son: libre concurrencia de oferentes, igualdad de oferentes, sujeción del proceso licitatorio al pliego de condiciones, publicidad, transparencia y selección objetiva del mejor postor ${ }^{35}$. Teniendo en cuenta lo anterior, el pliego constituye la principal fuente de derechos y obligaciones de los sujetos de la licitación, cuales son la entidad pública licitante y sujetos postores u oferentes.

Otras modalidades la constituyen la licitación privada, más apropiada para la contratación de las empresas de economía mixta; la subasta inversa, que es un sistema de licitación por el cual se declara postor ganador al competidor que ofrezca el menor precio en un procedimiento de lanzamiento repetido de invitaciones a ofrecer por parte de la entidad pública licitante. Por su parte, la modalidad de acuerdo marco de precios, consiste en un contrato suscrito entre la autoridad estatal de contratación pública y proveedores de tracto sucesivo, en el cual se acuerdan las condiciones y precio del suministro de determinados bienes o servicios por un plazo dado. Esta forma de contratación se inserta en un proceso contractual en dos fases, donde la segunda de ellas consiste en la fijación de las condiciones específicas de suministro concreto de bienes al sector público, las cuales incluyen básicamente la cantidad y lugar de entrega ${ }^{36}$.

En China, la Ley de Invitación a Ofertas y Subastas Públicas, así como la Ley de Compras Públicas, establecen cinco modalidades, que son la invitación pública y la subasta por invitación, las más usadas, y otras tres de carácter especial: la negociación competitiva, la indagación por cuotas y las compras de única fuente ${ }^{37}$.

\footnotetext{
34 Reconocida en Colombia por el artículo 30 de la Ley № 80 de 1993:

"[...] procedimiento mediante el cual la entidad estatal formula públicamente una convocatoria para que, en igualdad de oportunidades, los interesados presenten sus ofertas y seleccione entre ellas la más favorable. Cuando el objeto del contrato consista en estudios o trabajos técnicos, intelectuales o especializados, el proceso de selección se llamará concurso y se efectuará también mediante invitación pública".

35 Véase Ramírez Duarte (2012), p. 100.

36 Sobre esta modalidad, consúltese: Consejo de Estado de la República de Colombia, Sala de lo Contencioso Administrativo. Proceso 54549.

37 La invitación pública está considerado como la modalidad básica -default method-, cuando no se aplican las restantes y consiste en la invitación pública a ofrecer con el objetivo de postulación de la
} 
Todas las modalidades de contratación pública están sometidas a la vigencia de determinados principios. Para la región, el Sistema Económico Latinoamericano ha erigido como tales el principio de competencia abierta y efectiva, que permite la asignación eficiente de recursos en la sociedad y el pleno acceso de las empresas a las compras públicas; así como el principio de transparencia. Estos son el resultado de una tendencia global hacia la formulación y convergencia en torno a principios generales de procedimientos de compras públicas y han sido igualmente reconocidos por la Convención de Naciones Unidas contra la Corrupción en su artículo $9^{38}$.

En el caso chileno, el marco normativo establece básicamente cuatro modalidades de contratación pública: la licitación pública, la licitación privada, los tratos o contratación directa y el convenio-marco. Las tres primeras establecidas en el artículo 5 y 7 de la Ley 19886, Ley de Bases sobre Contratos Administrativos de Suministro y Prestación de Servicios -más conocida como Ley de Compras Públicas-, y la última por el artículo 30 inciso d) y el Reglamento promulgado por el DS 250. La licitación, tanto pública como privada, constituye un Ilamado por parte del organismo de la administración a los proveedores para que oferten propuestas contractuales de las cuales se seleccionará la mejor conforme a bases previamente fijadas. La diferencia fundamental entre ambas consiste en el carácter abierto o cerrado del llamado a presentar propuestas, en el sentido de emitir una convocatoria pública y notoria a todos los proveedores -en el caso de la licitación pública- o a determinados proveedores concretos -en el caso de la licitación privada-.

Por otra parte, la contratación directa es una modalidad que carece del procedimiento licitatorio y en razón de la cual el organismo público decide el proveedor con el cual negociar el contrato público sin convocar a presentación de propuestas. Tanto la contratación directa como la licitación privada están sometidas a determinados supuestos de procedencia cuyo cumplimiento es condición previa para que el organismo público pueda iniciar procedimientos pre-contractuales bajo estas dos modalidades. La procedencia de la contratación directa requiere igualmente la fundamentación por parte de la entidad pública.

mayor cantidad posible de postores. La subasta por invitación es utilizada para bienes y servicios con requerimientos especiales solo proveídos por determinados oferentes: consiste en enviar invitaciones a ofrecer solo a un determinado grupo de oferentes. La negociación competitiva por su parte, se utiliza cuando una subasta ha quedado desierta al momento de expirar el plazo de presentación de ofertas; en este caso, se envían invitaciones a un grupo aún más reducido y se establece un proceso de negociación privada con cada oferente que pueda presentarse. La indagación por cuotas consiste en la adquisición de bienes de caracteres homogéneos y estandarizados al postor que presente el precio más bajo. Por último, las compras de única fuente, como su nombre lo indica, son relevantes en situaciones de emergencia o cuando no existe un suministrador disponible. Sobre el tema, véase Gong y Zhou (2015), p. 67.

38 Véase Sela (2015), p. 9. 
Los supuestos de procedencia de los tratos directos están vinculados a la necesaria celeridad y eficacia de la administración en la gestión pública, las cuales por determinadas razones requieren procedimientos contractuales más expeditos.

Otra característica normativa que destaca a los tratos directos es su exclusión de la competencia del Tribunal de Contratación Pública. Se ha sostenido que el artículo 24 de la Ley de Bases de Contratación sobre la competencia de dicho tribunal incluye solo a las licitaciones, consecuentemente se excluyen de la misma los casos de conflictos que recaen sobre la modalidad de tratos directos.

Por último, debe mencionarse el convenio-marco, el cual si bien no es mencionado entre las modalidades del artículo 7 , ha sido reconocida de modo ad hoc en el artículo 30 y posteriormente desarrollado en el Reglamento de la Ley. El convenio-marco en sentido amplio, constituye un procedimiento de contratación pública caracterizado por la sujeción de todos los organismos públicos a la oferta de un proveedor previamente seleccionado para bienes y servicios específicos. Bajo este esquema, la entidad pública queda obligada a adquirir bienes y servicios de determinados proveedores indexados en una base de datos integrada por las empresas del sector privado que han suscrito previamente un convenio-marco al efecto con la Dirección de Compras y Contratación Pública -DCCP-. Desde el punto de vista de los supuestos de procedencia, el convenio-marco se diferencia sustancialmente de los tratos directos. En el último caso se trata de una modalidad que actúa como residual, que procede solo cuando resultan improcedentes las demás modalidades y solo es primera opción de contratación ante determinados supuestos taxativamente enumerados por la norma.

El propósito fundamental del convenio-marco como procedimiento contractual es la consolidación de las compras sobre productos o servicios estandarizados y altamente demandados por una parte sustancial de los organismos de la administración pública, de modo que se logran mejores condiciones de negociación como resultado de la magnitud de la compra y se garantiza la mejor oferta posible. Desde el punto de vista procedimental se distinguen dos fases: la primera relativa a la concertación del propio convenio-marco por medio de licitación entre la DCCP y los proveedores y la segunda que corresponde a la emisión de la orden de compra por parte de la entidad pública interesada en la adquisición de bienes y servicios al amparo del citado convenio.

El convenio-marco supone una ventaja directa en razón de la cual permite la consolidación de las compras públicas y con ello una mejora sustancial en la negociación de las condiciones de contratación como efecto del volumen del contrato, lo cual redunda en beneficios financieros para el Estado. Adicionalmente, deben mencionarse al menos tres ventajas indirectas; entre ellas, el ahorro en los costos generales y de transacción debido a la economía 
escala que se deriva de esta modalidad, una mayor eficiencia en la gestión pública al concentrarse la negociación y gestión del contrato en una sola entidad especializada y por último, la disminución en el riesgo de colusión.

\section{Definición de colusión en compras públicas y sus manifestaciones}

La colusión en compras públicas -o bidrigging en derecho anglosajón-, se define como las prácticas o acuerdos entre postores oferentes en un proceso de licitación convocado por una institución pública, encaminado a vulnerar el principio de competencia abierta y eficaz, en detrimento del interés patrimonial del Estado y en beneficio directo a los postores parte del acuerdo ${ }^{39}$. La determinación de colusión en compras públicas no es una tarea fácil; esto ha sido reconocido por varios autores ${ }^{40}$.

Las formas son de diversa índole y pueden manifestarse tanto en el proceso licitatorio como durante la ejecución del contrato público. En el primer caso, deben mencionarse las posturas encubiertas -coverbidding-, también conocidas como oferta de resguardo, oferta complementaria u oferta simbólica ${ }^{41}$. Se trata de un acuerdo encaminado a simular un escenario de subasta en licitación por medio de algunos de los fenómenos o conductas siguientes: presentación de una oferta más elevada o con condiciones leoninas o sin cumplir requerimientos legales, respecto del que ha sido designado para que gane la licitación; o posturas formuladas en términos por los cuales no tienen posibilidades reales de salir vencedoras. La finalidad de las posturas encubiertas es simular una competencia ante el órgano convocante.

En segundo lugar, merece atención la supresión de ofertas -bidsuppression-: conducta consistente en la presentación inicial de varias posturas y retiro sobrevenido de una o grupo de ofertas para allanar el camino al postor-ganador designado en el acuerdo colusorio. También se manifiesta como la presentación

\footnotetext{
39 Entre los autores chilenos, Tapia conceptualiza la Bid Rigging no como colusión en compras públicas, sino como presentación de ofertas conjuntas en subasta -colllusivetendering-. Véase TAPIA (2009), p. 7.

40 Sirva de muestra la siguiente aclaración:

"Sobre la conducta específica de colusión en licitaciones, es importante tener en cuenta que el límite entre lo permitido y lo prohibido es bastante indeterminado, pues muchas acciones desplegadas por los competidores, son consecuencia del funcionamiento del mercado. Así las cosas, si mi competidor sube precios o actúa de determinada manera dentro del mercado, yo debo tomar una reacción que en muchos casos será una conducta similar. En estos casos, no podemos hablar de una conducta prohibida y por ende, sancionable". Véase Ramírez Duarte (2012), p. 262.

41 En China se le conoce como peibiao. Otras de las prácticas de colusión en el mercado de compras públicas en China es el zizhiguakao, consistente en presentar oferta por interpósita persona, es decir, simular el sujeto postor. En esta modalidad, el sujeto que presenta la oferta y que no reúne los requisitos para presentarse, actúa en virtud de un acuerdo oculto con otra empresa que sí reúne tales requisitos y se presenta como postor en interés ajeno. Véase Gong y ZHou (2015), pp. 71, 72.
} 
de una postura conjunta en una situación de probable y razonable presentación de postura simple. Este tipo de acuerdos pretende constituirse en un mecanismo de presión contra la entidad convocante, para aceptar la postura que queda después de la retirada del resto de las ofertas, a partir de la necesidad e interés de la administración en lograr la solución a los intereses públicos en juego.

En tercer lugar, clasifica como modalidad de colusión, la rotación de ofertas -bidrotation-: mecanismo colusorio compuesto en el cual se aplican sucesivamente varias posturas encubiertas, supresión de ofertas o asignación de mercados, con la particularidad que en cada una de las modalidades sucesivas mencionadas, se rota la posición de postor-ganador. En este sentido, puede hablarse de rotación simple, cuando se asignan las convocatorias en igual número para cada postor que participa en la colusión. En la rotación por ingreso, se asignan las convocatorias a ganar a cada postor según el principio de igualdad de ingresos para cada uno, de modo que la frecuencia de convocatorias ganadoras para cada uno puede variar según la cuantía que aporta cada licitación. En la rotación por entidad, la asignación del número de convocatorias por postor designado se realiza en función de la equidad de ingresos considerando las dimensiones de los postores parte del acuerdo.

Por último, la asignación de mercados -marketallocation-, constituye un acuerdo colusorio en el cual las partes se distribuyen el mercado de licitaciones públicas, con el propósito de disminuir los costos asociados a las operaciones. Esto significa que las partes del acuerdo colusorio acordarán asignarse las licitaciones públicas en razón de un criterio de cercanía geográfica entre instalaciones y logística del postor respecto del área a prestar el servicio o suministrar el producto. Con seguridad, esto implica una reducción considerable del costo operacional, por medio de la cercanía territorial y adicionalmente, por el efecto restrictivo de la competencia que se deriva de dicho acuerdo. Las formas típicas en que se manifiesta esta modalidad son por medio de la abstención de producción o venta de productos distintos a los acordados en determinada zona o área geográfica, así como por medio de acuerdos de no ingresar en nuevo mercado. También se manifiestan por medio de postores fantasmas, que son empresas que participan regularmente en procesos de licitación y nunca logran resultar vencedoras ni se les adjudica ningún contrato.

Las cuatro modalidades anteriores de colusión se manifiestan en el proceso licitatorio, sin embargo, durante la ejecución del contrato mismo pueden darse estas prácticas. De modo particular, el postor-ganador de la licitación puede ejecutar un acuerdo colusorio por medio de la subcontratación parcial outsourcing hacia los postores perdedores, así como por medio de una cesión parcial o total del contrato. De esta manera, la colusión continúa después de la adjudicación del contrato público y durante su ejecución, de modo que las empresas que 
forman parte del acuerdo colusorio se garantizan una participación por medio de la subcontratación.

\section{Evidencia indiciaria y condiciones de mercado favorables a la colusión}

Las prácticas y conductas colusorias, amén de difícil demostración, son deducibles a partir de determinados indicios en el comportamiento de las empresas y del mercado. Varios documentos y textos doctrinales se han dedicado a la enumeración de tales conductas, con el propósito de facilitar la labor de investigación y determinación de dichas prácticas. De ellos, resulta particularmente importante el documento "An Antitrust Primer for Federal Prosecutors", del Departamento de Justica de los EE.UU., el cual ha servido de guía para la redacción de los Lineamientos de la Organización para la Cooperación y el Desarrollo Económico y otros documentos de análoga importancia ${ }^{42}$.

Las evidencias indiciarias se clasifican en relación con las posturas, en relación con el precio o demás elementos de la oferta, y en relación con la formalidad de la oferta. En el primer caso, los indicios de colusión en relación con las posturas son como siguen, y sin ánimo exhaustivo: la presencia de escasos oferentes cuando es razonable esperar un mayor número de posturas en licitación, la no presentación de un postor habitual, un récord o historial nulo de licitaciones ganadas por un postor, la presentación de una postura conjunta por medio de unión temporal de empresas o asociación ad hoc en circunstancias en que es posible y razonable esperar la presentación de posturas simples por cada empresa, recurrencia de una empresa ganadora en todas las licitaciones o en aquellas que responden a un patrón determinado de carácter geográfico, y la presentación de postura por empresa sin capacidad instalada para ejecutar el contrato público.

En el segundo caso, relativo a los indicios de colusión en relación con el precio o demás elementos del pliego, pueden manifestarse por medio de la presentación de varias ofertas cuyo precio se ubica ligeramente por encima del precio del eventual postor-ganador designado en el acuerdo colusorio, la presentación de posturas bajo términos y condiciones inaceptables por la entidad convocante, la repentina caída del precio ofertado al momento de entrar un nuevo postor en la convocatoria o una nueva empresa en el mercado, los movimientos bruscos y homogéneos de precios entre los competidores sin justificación en la estructura de costos, diferencias sustanciales entre precios ofertados para igual producto en distintas posturas, fijación colectiva por las empresas participantes de precios por encima del máximo declarado en la oferta, la dinámica líder-seguidor, entre otras.

42 Véase OCDE (2015), p. 50. 
Debe destacarse en particular un comportamiento dentro de la categoría de los indicios en relación con el precio o demás elementos de la oferta: es el intercambio de información entre postores. Esta conducta no constituye un indicio sino una prueba plena, en carácter de smoking-gun, dado que regularmente la ley establece en estos casos la presunción de colusión. En tercer lugar, deben mencionarse los indicios de colusión en relación con la formalidad de la oferta, las cuales aluden a la similitud no razonable en la papelería, tipografía, terminología u ortografía en la documentación presentada por varios postores.

Amén de los indicios de colusión, debe mencionarse la existencia de condiciones de mercado favorables a esta práctica, la sola presencia de los mismos no constituye prueba plena de la existencia de una conducta colusoria, pero la concurrencia de varios indicios y condiciones de mercado, da lugar a una razonable certeza o a razones fundadas para estimar la existencia de un acuerdo colusorio. Pueden mencionarse como condiciones de mercado favorables a la colusión, vinculadas a la situación de los postores-oferentes, las siguientes: elevadas barreras de entrada, escasos oferentes o situación consentida de monopolio, asociación institucionalizada con intensa actividad de los proveedores o activismo gremial, fácil constitución de uniones temporales de empresas, entre otras.

En relación con la situación de los compradores, se cuentan como condiciones de mercado favorables, la diversidad de oferentes y la fácil identificación de los mismos. En relación con los productos, las condiciones de mercado que motivan o coadyuvan a los acuerdos colusorios son las ofertas públicas sobre commodities y la carencia o indisponibilidad de productos sustitutos. En relación con la situación del mercado, deben mencionarse la existencia de una demanda sostenida y sustancial, así como una alta frecuencia de licitación, estabilidad y predictibilidad en el mercado. Por último, la práctica de subcontratación de proveedores que participaron en las posturas, además de ser indicio es condición favorable a la colusión.

\section{Reconocimiento normativo y casuística}

Una de las cuestiones asociadas a la colusión en compras públicas y su reconocimiento normativo es la dualidad derecho de competencia y contratación pública. Esta no se manifiesta en el ámbito del análisis económico, donde existe una suerte de campo común que permite un enfoque integral del tema, no restringido a una disciplina solamente. Amén de la dualidad mencionada, la colusión en las compras públicas ha sido tratada normativamente de dos maneras. Por un lado, algunos Estados la reconocen dentro de la categoría más general de colusión (Estados Unidos, Reino Unido), mientras otros le conceden un tratamiento legislativo específico (Canadá, Noruega, Hungría) ${ }^{43}$.

${ }^{43}$ Véase OCDE (2015), p. 25. 
En el caso de EE.UU., estas prácticas encuentran represión legal en el derecho estatutario, particularmente la Ley de Competencia en la Contratación -Competition in Contracting Act-, así como en el Reglamento Federal de Adquisiciones -Federal Acquisition Regulation $-^{44}$. A pesar de tratarse de una economía de fuerte impronta liberal cuya legislación antitrust, en relación a la europea, puede ser la mayor de las veces deferente respecto de la concentración económica, no puede negarse la existencia en sus antecedentes de una etapa Ilamada estructural, en la cual el derecho de competencia incrementó su función moduladora de la actividad de la gran empresa ${ }^{45}$.

El caso chino, como se dijo anteriormente, resulta un modelo a analizar. El gigante asiático inicia la dinámica reguladora Estado - sector privado a partir de las reformas económicas de los años 80, caracterizado por una primera etapa experimental, una segunda etapa de regulación puntual del experimento y una tercera etapa de generalización por medio de un marco normativo codificado y con propósito de estabilidad ${ }^{46}$.

\footnotetext{
44 Véase OCDE (2015), p. 98.
}

${ }^{45}$ Baker da cuenta de tres etapas en el derecho de competencia de los EE.UU.: la etapa clásica, la etapa estructural y la etapa de la Escuela de Chicago. La etapa estructural, aquella de mayor grado de regulación y control del poder de mercado en EE.UU., coincidió con la recuperación económica post-Depresión, a partir del año 1938 junto a la acción del Comité Nacional Económico Temporal -Temporary National Economic Committee- y los esfuerzos de Thurman Arnold, Asistente Antimonopolio del Fiscal General. Estos esfuerzos en reforzar la regulación y el control comienzan a ver sus frutos en las decisiones US $V$ Socony-Vacuum Oil Co., 310 US 150, 1940 y US v Aluminium Co. of America-Alcoa, 148 F.2d 416, 2nd Circ, 1945, así como en las enmiendas Cellar-Kefauver a la Ley Clayton.

En cualquier caso, la esencia de la etapa estructural no consistió en la regulación y control sin más del poder de mercado, sino en un tácito entendimiento nacional -informal national understanding-, en un acuerdo producto de una negociación no explícita entre el Estado y su interés en la recuperación del poder de compra del consumidor y la gran empresa y su interés en la recuperación del margen de utilidades. El sentido de dicha negociación determinó la liberación de la gran empresa de regulación jurídica pero manteniendo un control relativamente fuerte del poder de mercado bajo vigilancia antimonopolio. Todo un quid pro quo:

"El interés del consumidor hacia la izquierda ha favorecido un enfoque más intervencionista, redistributivo, regulatorio y de planificación nacional, mientras que el interés del productor hacia la derecha ha favorecido un enfoque menos intervencionista, de laissez-faire y autorregulatorio por la propia industria, tolerante de un mayor ejercicio del poder de mercado. Como producto de un acuerdo informal entre ambos intereses, se gestó un enfoque centrista que permitió a la economía lograr una mayor eficiencia que la que pudiera lograrse con alguno de los enfoques extremos". Véanse BAKER (2016), p. 213; BAKER (2006), p. 483.

46 La primera etapa experimental se desenvolvió básicamente en la década de los 80, cuando inició el desarrollo de un sector privado proveedor de productos y servicios de diverso tipo, y de una administración pública requerida del uso eficiente de recursos financieros, por lo cual comienzan a darse las primeras experiencias de compras públicas en el sector de la construcción. Estas resultaron exitosas: reducción de tiempo y costos en los proyectos contratados, incremento en la transparencia y reducción de la discrecionalidad de los funcionarios locales para adjudicar proyectos. Como resultado de ello, a finales de los 80 , la fase experimental se había extendido a otros mercados de 
En el caso español, la colusión en compras públicas está prohibida por el artículo 1.1 de la Ley 15 de 2007, el artículo 1 de la Ley de Contratación de Servicios Públicos y el artículo 101.1 del Tratado de Funcionamiento de la Unión Europea, que es norma comunitaria. Los casos de colusión generalmente aluden a obras de infraestructura y adquisición de medicamentos. Cabe mencionar como ejemplos, un acuerdo de fijación de precios entre 53 empresas de construcción en convocatorias a pavimentación de carreteras de interés nacional (CNC-S/0226/10), un acuerdo de fijación de precios entre empresas proveedoras de material radiológico medicinal para un importante hospital (TDC-565/03/04), una presentación conjunta de posturas disfrazada por la constitución de una unión temporal de empresas para el manejo de residuos biológicos (CNC-S/0014/07), un acuerdo de fijación de precios entre empresas farmacéuticas proveedoras de vacunas antigripales a una entidad autonómica de salud (TDC-395/97), un acuerdo de distribución del mercado de licitaciones públicas entre empresas proveedoras de servicios de venta, instalación y reparación de ascensores y escaleras mecánicas (DG-COMP/E-1/38.823/2007) y un acuerdo para la distribución global de convocatorias y fijación de precios de instalación de Gas Insulated Switchgear excepto para EE.UU. y Canadá (DG-COMP/38.899).

En el ámbito latinoamericano, debe mencionarse el caso de México, donde la colusión en compras públicas es muy frecuente en el área de los medicamentos de uso hospitalario, al detectarse coordinación de posturas ante licitación por el Instituto Mexicano del Seguro Social, en el período 2002-2007. Para la determinación de tal conducta, se estableció como relevante, un Mercado I (insulina) y un Mercado II (sueros y soluciones electrolíticas). Los indicios que en tal caso indicaban colusión resultaron ser las comunicaciones entre los directivos de las empresas postoras en cantidad suficiente y coincidiendo con los períodos de presentación de posturas, reuniones entre directivos en la asociación gremial de empresas farmacéuticas, coincidencia de ganadores, altos márgenes de utilidad entre empresas farmacéuticas que admitía mejores posturas, entre otros. De igual forma, debe destacarse como indicio de importancia, la identificación

compras públicas como maquinaria, suministros médicos, proyectos de investigación científica y de infraestructura financiada con inversión extranjera.

La segunda etapa se caracterizó por la regulación del experimento económico, por medio de normas sobre compras públicas. Las primeras reglas formales de corte local en este sentido fueron dictadas por la ciudad de Shenzhen, junto a regulaciones específicas del Ministerio de Finanzas. Por último, la tercera etapa inicia en el año 2000 con la promulgación de la Ley de Invitación a Ofertas y de Subasta Pública en dicho año; y, la adhesión a la OMC en el año 2001, y con ello, al Acuerdo de Compras Públicas, que exige la apertura del mercado de adquisiciones públicas a las empresas extranjeras. En razón de ello se dicta la Ley de Compras Públicas de 2003, sin derogar íntegramente la normativa anterior.

Sobre la evolución, regulación, praxis y perspectivas de las compras públicas en China, véase GoNG у Z HOU (2015), р. 66. 
de un período colusorio y un período competitivo en el comportamiento de los precios en postura ante la entrada de un nuevo competidor.

En el caso colombiano, la consagración normativa de las prácticas restrictivas de la competencia y particularmente de la colusión, encuentran mayor dispersión normativa. Es así que deben mencionarse la Ley 155 de 1959, la Ley 1340 de 2009, el artículo 47, numeral 9 del Decreto № 2.153 de 1992, a partir de la cláusula general del art. 1, Ley № 155 de 1959; el Decreto № 2.153 de 1992, y el Decreto No 3.523 de 2009 modificado por el Decreto $N^{0} 1.687$ de $2010^{47}$. Esta situación de dispersión también se refleja en las competencias y atribuciones de la Superintendencia de Industria y Comercio: el artículo 6 de la Ley $N^{\circ} 1.340$ de 2009 establece la competencia general exclusiva de la SIC para investigar y perseguir la colusión, mientras que los artículos 44 y 47 del Decreto № 2.153 de 1992 aluden igualmente a esta práctica restrictiva de la competencia. Entre las formas de colusión reconocidas en la norma colombiana, encontramos la colusión en licitaciones, en concursos, efecto distribuidor de adjudicaciones de contratos, efecto distribuidor de concursos y el efecto de fijación de términos de propuestas.

De la misma manera, la colusión resulta ser un tema de importante tratamiento por la jurisprudencia constitucional. Ramírez Duarte menciona como relevante la sentencia C-415/1994, magistrado ponente: Cifuentes Muñoz, la cual sostiene que la intención del legislador en materia de represión de la colusión en las compras públicas es la promoción de "condiciones más favorables y provechosas para el interés público", "asegurar igualdad de oportunidades entre los particulares para contratar con el Estado" y "una activa y honesta competencia". De esta manera, la jurisprudencia constitucional colombiana reconoce el "mercado honesto" y la igualdad de oportunidades para los empresarios, y reconoce, para el caso del ámbito público, como valor adicional: el interés social representado en el Estado como comprador en el mercado.

Resulta interesante destacar que la autoridad en derecho de competencia en Colombia ha establecido en al menos una ocasión, un criterio de colusión encaminado no solo a la represión por los efectos, sino además, por la mera probabilidad de su alcance. En este sentido, la autoridad ha determinado, en la Resolución 1055, 19/1/2009, Caso Intersystem, Buitrago Camargo y Vega Cruz, que existe colusión solamente con el hecho de que se persiga incrementar la probabilidad de adjudicación ${ }^{48}$.

\footnotetext{
47 Artículo 47, numeral 9, Decreto № 2.153 de 1992: "Para el cumplimiento de las funciones a que se refiere el artículo 44 del presente decreto se consideran contrarios a la libre competencia, entre otros, los siguientes acuerdos: [...] Los que tengan por objeto la colusión en las licitaciones o concursos o los que tengan como efecto la distribución de adjudicaciones de contratos, distribución de concursos o fijación de términos de las propuestas".

48 "Resulta necesario indicar, que el hecho de que el mecanismo colusorio adoptado por los investigados, no fuera especialmente eficaz para obtener la adjudicación de los contratos, no permite
} 
Del mismo modo, la autoridad colombiana en derecho de competencia ha sido enfática al declarar la "extraña coincidencia" de precios entre postores en licitación, como conducta colusoria. En este sentido, se investigan las posturas con precio irrisorio, irracionalmente bajos para el giro de comercio y que necesariamente implican operaciones a pérdidas para el postor ${ }^{49}$. Esta práctica de ofertar con precios irrisorios se hace con el objetivo de defraudar el procedimiento de selección objetiva de la mejor oferta.

En Ecuador, la colusión en compras públicas se considera una práctica prohibida expresamente por el artículo 11, numerales 6 (para la colusión horizontal) y 21 (para la colusión vertical) de la Ley Orgánica de Regulación y Control del Poder de Mercado. Asimismo, el artículo 8.4 del Reglamento de la Ley Orgánica dispone la presunción de práctica restrictiva vinculada a las compras públicas junto al artículo 41, que establece la obligación de la Superintendencia de Control del Poder de Mercado -SCPM- en implementar mecanismos de vigilancia y monitoreo de los procesos de contratación pública ${ }^{50}$.

De las recientes tendencias en materia de colusión -bid-rigging- en EE.UU., cabe destacar como nueva condición favorable a la misma la participación accionaria horizontal -horizontal shareholding-.

\section{El Fenómeno de la participación accionaria horizontal en el derecho de competencia}

Se trata del efecto anticompetitivo que se deriva de la participación accionaria horizontal por un grupo reducido de inversionistas institucionales ${ }^{51}$. Para

prescindir del reproche, mucho menos cuando los investigados declararon expresamente el objeto perseguido, cuál era el de coludir en los procesos de contratación en los que participaron, absteniéndose de competir entre ellos en la instancia previa a la evaluación de las propuestas con el compromiso de subcontratar posteriormente entre ellos" (SIC, Res. 1055, 19/1/2009, Caso Intersystem, Buitrago Camargo y Vega Cruz).

49 Sobre el tema, téngase en cuenta lo siguiente:

"Teniendo en cuenta las reglas previamente establecidas en el Pliego de Condiciones, así como los resultados históricos de licitaciones anteriores con mecanismos de asignación de puntaje similares al de este proceso, es posible concluir que para tener una oferta competitiva en el mismo, es decir, una oferta con posibilidades de ser adjudicatario, los precios ofrecidos debían situarse un rango de valores cercano al 99\% de los precios oficiales". Véase Ramírez DuARTE (2012), p. 110.

50 Adicionalmente, en Ecuador están vigente otras disposiciones normativas que prohíben la colusión en las compras públicas: Ley Orgánica del Sistema Nacional de Contratación Pública (arts. 1, 4, 5, 6.5, 9, 10, 14, 15, 25.1, 25.2, 27, 29), Ley Orgánica de la Función de Transparencia y Control Social (arts. 3.3, 3.5, 3.7, 4.1 , 4.3, 4.4 , 7.1, 7.3), Ley Orgánica de la Contraloría General del Estado (arts. 1, 2, 33 y 54), Ley Orgánica de la Procuraduría General del Estado (art. 3, e, g, 5, g) y Decisión 668 CAN, Plan Andino de Lucha contra la Corrupción.

51 Algunas de las denominaciones que recibe dicho fenómeno de reciente interés académico: titularidad paralela de inversionistas institucionales en industrias concentradas - parallel holdings of institutional 
ser más exactos, consiste en el fenómeno por el cual las principales empresas en un mercado relevante, cuentan en su estructura accionaria con un número determinado y muy reducido de inversionistas comunes con una cuota de participación sustancial ${ }^{52}$. Este fenómeno no califica como concentración económica en sentido propio pues no se trata de una fusión o de un conglomerado de entidades controladas, sino como participación accionaria horizontal o simplemente participación cruzada ${ }^{53}$. El actual marco normativo antimonopólico impide su represión dada la dificultad para su tipificación, generando un posible conflicto con la libre adquisición y venta de títulos en una economía de libre mercado. No llega a ser una concentración económica propiamente dicha, pero tampoco integra una conducta colusoria propia; está a mitad de camino entre uno y otro.

La estrategia de persecución asumida por parte de las agencias especializadas en EE.UU. ha sido aumentar la lupa de la investigación y perseguir a través de la colusión por medio de la fijación de precios, lo cual constituye la conducta típica de los competidores involucrados en este fenómeno. Dicho esto, los inversionistas institucionales encuentran excelentes incentivos para evitar una guerra de precios, reducir sus actividades de $\mathrm{I}+\mathrm{D}+\mathrm{i}$ y cooperar activamente en la fijación de precios, aunque no resulta del todo necesario. De igual forma, encuentran excelentes incentivos para minar por medios deshonestos la actividad de un competidor nuevo o no participado por el grupo de inversionistas institucionales, que pretenda incrementar su cuota de mercado a través de conductas competitivas como la reducción de precios, el incremento del suministro a la demanda o el valor tecnológico añadido ${ }^{54}$.

investors in concentrated industries-, titularidad común de inversionistas institucionales-common holdings of institutional investors-(Davidson), titularidad cruzada-cross-holdings-, entre otras. Baker se opone a la denominación de Participación Horizontal, propuesta por Elhauge y a su vez propone denominar el fenómeno como Titularidad Superpuesta de Inversionistas Financieros -Overlapping Financial Investor Ownership-. Por otra parte, O’Brien y Salop denominan el fenómeno como Titularidad Parcial por Rivales Horizontales -Partial Ownershipby Horizontal Rivals-Al respecto, Véase por todos, BAKER (2016), p. 213.

52 Elhauge describe elocuentemente el fenómeno a partir de datos empíricos: en el mercado de aerolíneas, siete inversionistas controlan cuotas significativas en United Airlines, Delta Airlines, JetBlue Airlines y Southwest Airlines, las cuales a su vez detentan una cuota más que significativa del mercado relevante. En el mercado de la banca, cuatro inversionistas (BlackRock, Vanguard, State Street yFidelity) son titulares de cuotas relevantes de participación accionaria en JPMorgan Chase, Bank of Americay Citigroup, quienes a su vez tienen una cuota nada despreciable en el sector bancario. Lo mismo ocurre en el mercado relevante de farmacias y de software para PC, véase ElHAuGE (2016), pp. 1.267 y 1.268. Por su parte, Baker describe el fenómeno en los mismos mercados. Véase BAKER (2016), p. 213.

53 La descripción precisa de este fenómeno se puede encontrar en dos textos de reciente publicación, uno de carácter académico, véase ElHAUGE (2016), p. 1.267; y otro de carácter más bien periodístico o de comentario económico; véase DATTA (2015), p. 2.

54 Esta conducta es producto de un fenómeno de concentración económica no definido como tal por la ley, pero que la evidencia empírica demuestra su existencia al obtenerse un Índice Herfindahl- 
Como resultado, los autores citados reportan auténticas prácticas anticompetitivas como colusión y "follow the price leader" ${ }^{\prime \prime 5}$. El secreto a voces consiste en que tales inversionistas ejercen su derecho a voto conforme su mejor interés empresarial y asistidos por la administración. Cada gestor de cada empresa por separado recomienda a los accionistas una conducta anticompetitiva dada la información pública de que tales accionistas participan también en las empresas competidoras ${ }^{56}$. He aquí entonces dos hechos inevitables e irreprimibles por la ley: el carácter público de la información sobre la estructura accionaria de los competidores en el mercado y el ejercicio del derecho al voto por los accionistas en su mejor interés empresarial. Estos son los elementos que crean el marco propicio para una férrea resistencia a la competencia en un mercado con escasos competidores y participación accionarial cruzada por un grupo reducido de inversionistas.

Este fenómeno, particularmente estadounidense, es de singular importancia para América Latina, donde el carácter primario-exportador de las economías así como otras vulnerabilidades estructurales, tienen por efecto de mercados con escasos competidores y una más intensa participación como inversionista de grupos económicos institucionales de raíz familiar ${ }^{57}$. Se le han identificado al menos tres efectos, negativos para los mercados relevantes en EE.UU. y muy nocivos para América Latina. En primer lugar, recompensa a la administración

Hirschman por encima de 2500: el actual umbral de concentración admitido por las autoridades de competencia en EE.UU. Véase Elmauge (2016), p. 1.271.

55 Baker da cuenta de varios estudios empíricos que sostienen el incremento de conductas facilitadoras de coordinación y prácticas restrictivas de la competencia así como de exclusión o prevención de entrada de competidores. Véase BAKER (2016), p. 215.

56 Dicho en términos más explícitos: "Si existe una sustancial participación accionaria horizontal, los incentivos [a competir] se reducen. La administración de las empresas pares participadas no necesitan coludir o cartelizarse. Su estrategia es determinada por retroalimentación proveniente de los principales accionistas-inversionistas quienes tienen posiciones en varias de las empresas". Véase DATTA (2015), p. 2.

57 Tales efectos nocivos han sido denunciados por varios autores a nivel internacional, entre ellos cabe destacar al propio Elhauge que enarbola la relación entre el fenómeno de participación horizontal como causa del progresivo incremento del poder de mercado de las grandes empresas en EE.UU. desde la década del 80 y el consecuente incremento en la desigualdad de ingresos. Concuerdan con Elhauge, otros autores como O’Brien y Salop, así como Azar, Schmalz y Tecu. Por su parte Baker, si bien acepta la relación entre el fenómeno de titularidad superpuesta de inversionistas financieros -como le llama a diferencia de Elhauge- y el incremento sostenido en el poder de mercado de las grandes empresas; también sostiene que dicha relación no es lineal y que deben valorarse el aporte a dicho incremento que puede ser generado por otros factores como la transformación paulatina del derecho de competencia desde la década del 70 por parte de la Corte Suprema siguiendo los postulados de la Escuela de Chicago, los cambios tecnológicos de finales del siglo XX e inicios del siglo XXI asociados a la fuerte protección legal a la propiedad intelectual y la "respuesta desproporcionada del sistema político de los EE.UU. hacia las preocupaciones del capital" (sic). Véase BAKER (2016), pp. 214-216; O’Brien y Salop (2000), p. 559; Azar y otros(2016), p. 4 
no por los resultados de la empresa, sino de la industria en general. En segundo lugar, explica cómo es posible que los incentivos fiscales y estímulos económicos a las empresas no se revierta en incremento del $\mathrm{I}+\mathrm{D}+\mathrm{i}$, de la producción y del empleo ${ }^{58}$. En tercer lugar, promueve la inequidad en la distribución de la riqueza minando la capacidad adquisitiva del consumidor.

La reciente preocupación en EE.UU. por prácticas de este tipo se derivan de otra nueva tendencia caracterizada por el cambio de paradigma en el análisis económico de las normas antitrust: del paradigma precio-eficiencia al paradigma de la opción del consumidor.

Varios estudios recientes han mostrado la enorme importancia que se le ha dado al factor precio y la escasa importancia relativa que se ha dotado a factores de interés del consumidor no vinculados a este ${ }^{59}$. Averitt y Lande, exponen una clara dicotomía entre dos paradigmas de análisis económico en materia antitrust. el enfoque precio-eficiencia y el enfoque de la opción del consumidor -priceefficiency versus consumerchoice-. En el primer caso, estamos en presencia del típico y común análisis de las conductas anticompetitivas que se realiza tomando como variable fundamental el precio, sea como factor en el análisis de concentración de empresas, de la eficacia de las prácticas anticompetitivas en las cuales la fijación de precios es la más importante o de la eficacia en el abuso de posición dominante por medio de la desviación de precios en el mercado relevante ${ }^{60}$. En este sentido, dicho modelo sostiene que todo el derecho de competencia tiene por objetivo prevenir el poder de las empresas para controlar

\footnotetext{
58 Estos son los aspectos que motivan la necesidad una política y norma de derecho de competencia en América Latina ajustadas a la realidad de la región:

"En conclusión, las economías de países en vía de desarrollo son portadoras de estructuras de mercado con características muy propias, y sobre las que la política de competencia debe actuar de forma diferente de su accionar en economías más perfectas. Por ejemplo, un gran número de las economías latinoamericanas carecen de cultura de competencia; poseen una importante concentración del poder económico y político en pocas manos que les permite a las organizaciones capturar las instituciones y de otro lado dificulta la independencia de las autoridades; tampoco poseen, desde la perspectiva de los Estados, los recursos financieros y humanos para consolidar instituciones sólidas que actúen contra los comportamientos anticompetitivos; hechos todos que unidos generan una mezcla perfecta para capturar los beneficios de la apertura económica por unos pocos e incrementar las diferencias económicas y sociales entre los ciudadanos".

Véase Álvarez-Londoño (2008), p. 256.

59 Resulta paradigmático el estudio de Averitt y Lande (2007), p. 176.

60 En este sentido, los autores citan al menos dos casos que constituyen precedente y que sostienen el concepto de poder de mercado en la variable precio. El primero de ellos, NCAA $v$ University of Oklahoma Board of Regents, 468 US 85, 109, 1984, el cual sostiene que el poder de mercado es la habilidad para incrementar los precios por encima del que resultaría de un mercado competitivo. El segundo caso, US v E.I. Du Pont de Nemours \& Co., 351 US 377, 391, 1956, sosteniendo que el monopolio se define por su poder de control de precios.
}

Véase Averitt y LANDE (2007), p. 183. 
los precios. En cualquier caso, las bases del citado paradigma se encuentran en mercados orientados al comercio de productos estandarizados con escaso valor agregado o componente tecnológico-commodities-, típico de finales del siglo XIX y del siglo XX, cuando surge y crece el derecho de competencia.

Los estudios mencionados aluden al agotamiento del paradigma precioeficiencia. En este sentido mencionan al menos dos casos en los cuales el análisis económico a partir de dicho modelo arrojó resultados contraproducentes, con el objetivo de fomentar el avance tecnológico, la eficiencia de los mercados y de la asignación de recursos sociales, así como del bienestar del consumidor ${ }^{61}$. En razón de ello, proponen sustituir el modelo de análisis económico centrado exclusivamente en el precio por un modelo que pondere al mismo nivel otros factores como la innovación y la calidad ${ }^{62}$.

Este modelo se basa en el entendido de que el interés del consumidor no radica exclusivamente en el precio del producto, sino también en la diversidad u opciones que el mercado le otorga; diversidad que a su vez depende de la intensidad de investigación, desarrollo e innovación de productos que logren las ${ }^{61}$ Averitt y Lande mencionan la fusión entre Genzyme Corp. y Novazyme Pharmaceuticals. Entre los
años 1998 y 2001 , Genzyme llevó a cabo fuertes movimientos de adquisición de empresas farmacéuticas
que llevaban adelante procesos de investigación y desarrollo de la cura para la rara Enfermedad de
Pompe. Ante cada una de las adquisiciones, los procesos de I+D+i de las empresas adquiridas fueron
cerrando, manteniéndose únicamente el programa de investigación de Genzyme. Definitivamente, la
FTC accedió a la mencionada fusión aludiendo que la misma implica asignación eficiente de mayores
recursos en un solo programa de desarrollo por medio de la suma de esfuerzos financieros y de talento
humano, es decir, un efecto benigno en la sinergia de la investigación -benignresearchsynergies-, así
como un mayor incentivo económico para lograr el producto y colocarlo en el mercado. Por razones
de diversa índole entre las cuales destaca el enfoque de gestión aplicado por la empresa, el programa
de investigación no prosperó y se malogró el producto farmacéutico.
En este caso, sostienen Averitt y Lande, la FTC debió haber impedido la fusión y con ello, mantenida
la diversidad de programas de investigación por encima del ahorro en la asignación de recursos. La
Comisión ponderó los beneficios económicos asociados a la eficiencia en la investigación, reducción
de costos y posible colocación del producto a buen precio por encima de la diversidad de proyectos
de investigación con igual diversidad de enfoques de gestión. A la opinión de los autores, se trata de
un lamentable caso de aplicación errónea del enfoque precio-eficiencia.

Véase AveritT y LANDE (2007), p. 226.

62 En este sentido resulta particularmente relevante las tesis sostenidas por Pitofsky, Comisionado de la FTC y Kovacic en el mercado de la industria de defensa en los EE.UU.: "[calidad e innovación], en la industria de defensa, estos indicadores no vinculados al precio pueden ser tan importantes, incluso más, que el precio" (Pitofsky en su Declaración como Comisionado de la Competencia ante el Comité Judicial del Senado, Subcomité Antimonopolio, de Derechos de las Empresas y Competencia). De igual manera, en varias ocasiones el Departamento de Defensa-DoD- ha expresado la importancia como monopsonio, de contar con una industria capaz de proveer innovación en términos de mantener una ventaja tecnológica respecto de otras naciones de una generación o dos (Estudio de Capacidad de la Infraestructura Industrial de Defensa, presentado a la FTC por la Segunda Subsecretaria del Departamento de Defensa para la Política Industrial).

Véase Averitt y LANDE (2007), p. 219. 
empresas en el mercado relevante. El comportamiento complejo del consumidor dista mucho de la relación lineal precio-poder adquisitivo, sino que incluye la diversidad de oferta, la intensidad de la innovación e incluso consideraciones de carácter moral, ético y religioso ${ }^{63}$. Es por ello, que la infracción antitrust, conforme el paradigma precio-eficiencia es considerado como una actividad que restringe ilegítimamente las opciones en el mercado en relación con el precio, mientras que conforme el paradigma de la opción del consumidor, restringe además las opciones de este no vinculadas al precio.

Entre las ventajas que se le atribuyen al enfoque de la opción del consumidor, deben mencionarse su habilidad para dialogar sobre competencia con otros gobiernos y autoridades nacionales y comunitaria no solo en países desarrollados, sino en vías de desarrollo ${ }^{64}$; así como su habilidad para sensibilizar audiencias no expertas pero muy relevantes como el jurado en juicio, el Congreso y los electores. Por último, se le reconoce la eficacia en conectar los objetivos de protección del mercado de la legislación antitrust y los objetivos de protección del interés del consumidor, consagrado en la Ley de la Comisión Federal de Comercio ${ }^{65}$.

63 En este sentido, amerita atención el caso Dominican Santa Cruz Hospital, ante la FTC en 1994, en el cual se autoriza la fusión de dos centros hospitalarios en una comunidad concentrando alrededor de dos tercios de la cuota de mercado de los servicios médicos. El efecto de la fusión no resultó en un incremento del precio para el usuario, sino en la extensión de una política de atención de salud implementada por los dueños de dichas instituciones en el sentido de negar determinados servicios de salud sexual y reproductiva como la ligadura de trompas de Falopio, bajo consideraciones de índole religiosa. Esto constituye sin duda, una práctica de concentración de empresas que afecta de modo evidente la diversidad de ofertas al usuario en este caso que si bien no supone fijación de precios, sí implica la fijación de otras condiciones de transacción. Dicha solución sería válida conforme el enfoque precio-eficiencia, pero inválida conforme el enfoque de la opción del consumidor.

Véase AverITT y LANDE (2007), p. 179.

64 La capacidad de las instituciones de defensa de la competencia de EE.UU. para coordinar con las instituciones análogas europeas en una economía global donde la eficacia del derecho de competencia depende de otras instituciones extranjeras, recae cada vez con mayor énfasis en un entendimiento mutuo respecto de los valores del sistema de libre mercado. En este sentido:

"[El modelo de opción del consumidor] es particularmente útil para presentarlo a la Unión Europea como punto medio de convergencia de las políticas nacionales de las naciones industrializadas. La Unión Europea está menos comprometida que los EE.UU. en el paradigma precio-eficiencia. Las leyes europeas y el comportamiento institucional en la ejecución de la norma antitrust acogen un grupo de valores, y aunque la eficiencia está entre esos valores, no parece muy probable que las instituciones europeas se sientan cómodas descansando únicamente en el valor eficiencia". Véase AveritT Y LANDE (2007), p. 249.

65 Las tesis en torno a la importancia de la opción del consumidor en el derecho de competencia son sistematizadas bajo la nueva categoría "soberanía del consumidor". En este sentido, reconocen que el derecho de competencia y el derecho del consumidor tienen propósitos distintos pero complementarios dado que intentan garantizar, de formas distintas, que el mismo disfrute de dos elementos esenciales en el mercado: opciones y la capacidad para elegir entre ellas. El derecho de competencia busca la protección a la diversidad de opciones, condenando las prácticas restrictivas de la competencia que 
Retomando lo concerniente a la participación accionaria horizontal, como fenómeno resulta ser pernicioso para el consumidor, sin embargo, su mayor efecto nocivo recae en el ámbito de la contratación pública, dado que el grado de afectación producto de esta nueva tendencia en el mercado recae en los recursos financieros del Estado. En este sentido, las compras públicas en sus diversas modalidades se convertirán en el principal ámbito de manifestación de las consecuencias prácticas de fenómeno accionarial descrito, así como de la propia práctica colusoria.

La participación accionaria horizontal es una práctica ya consagrada en los mercados públicos en EE.UU. y de reciente advertencia por parte de la academia. En el caso de América Latina, a pesar de presentar mayores riesgos a la presencia de este fenómeno como resultado de la escasez de oferentes en el mercado público y los estrechos vínculos familiares que caracterizan al sector privado, no puede hablarse de una toma de razón-awareness- por parte de la institucionalidad protectora de la competencia en el mercado. Cabe mencionar este fenómeno sobre todo en las principales economías de la región en las que destaca Chile.

\section{Colusión en compras públicas en Chile}

La referencia a Chile no es superflua o banal. De los Estados de la región, Chile ha alcanzado un notable desarrollo económico y especialmente en el tejido empresarial, lo cual impacta de modo directo en una expansión del mercado por medio del auge de oferentes de diversos productos y servicios, no solo de orden primario sino en el ámbito de los servicios especializados y tecnologías con alto valor agregado ${ }^{66}$.

\subsection{Marco institucional y normativo de las compras públicas}

La contratación pública en Chile está regulada por un régimen jurídico integrado por varias leyes de carácter orgánico y general, la legislación relativa a cada órgano del Estado y un grupo de regulaciones de derecho administrativo de carácter reglamentario. Las más importantes y que integran el

\footnotetext{
buscan excluir o impedir la entrada de nuevos competidores y nuevas opciones de consumo. Por su parte, el derecho del consumidor protege la capacidad del cliente para la selección libre, razonable e informada del producto en el mercado, condenando la retención de información, el fraude manifiesto o el engaño por parte del productor.

Al respecto, véanse Averitt y LANDe (1997), p. 713; Averitt y LANDE (2007), p. 181.

66 Desde el punto de vista académico, vale destacar para el caso chileno al menos un estudio econométrico del fenómeno colusorio Martínez y Escobar (2011), pp. 385-417, así como dos estudios de casos: Araya Jasma (2012), pp. 223-241 y Araya JaSma (2014), pp. 314-354.
} 
marco institucional de la contratación pública en Chile son la Ley N No 18.575, Ley Orgánica Constitucional de Bases Generales de la Administración del Estado -en lo adelante, LOCBGAE-, promulgada el 12 de noviembre de 1986 y modificada sucesivamente; la Ley 19880, Ley que establece las Bases de los Procedimientos Administrativos que rigen los Actos de los Órganos de la Administración del Estado -en lo adelante, LBPA-, promulgada el 22 de mayo de 2003, la Ley $N^{\circ}$ 19.886, Ley de Bases sobre Contratos Administrativos de Suministro y Prestación de Servicios -en lo adelante, Ley de Compras Públicas-, promulgada el 11 de julio de 2003 y que cuenta con un texto de modificación diferida al 1 ro de abril de 2017 y la Ley No 19.653 sobre Probidad Administrativa aplicable a los Órganos de la Administración del Estado, promulgada el 3 de diciembre de 1999.

Entre las disposiciones de derecho administrativo de carácter reglamentario, cabe destacar como la más importante el Decreto $N^{\circ} 250$ que aprueba el Reglamento de la Ley No 19.886 de Bases sobre Contratos Administrativos de Suministro y Prestación de Servicios, promulgada el 9 de marzo de 2004 y modificado el 12 de mayo de 2015 por el Decreto № 1.410. Por otra parte, el Decreto Supremo № 1.312 del Ministerio de Hacienda, que establece el Sistema de Información de Compras y Contrataciones Públicas, promulgado el 22 de septiembre de 1999, y a partir del cual se crea posteriormente el portal chilecompra.cl.

Del marco normativo mencionado deben excluirse determinados supuestos y materias que caen bajo la norma especial. Conforme el artículo 3 de la Ley de Compras Públicas, caen en esta categoría de exclusión la contratación de personal, los contratos entre los propios organismos públicos y los que se celebren con organismos internacionales, los contratos sobre valores negociables e instrumentos financieros y aquellos sobre productos y servicios de defensa y orden interior. Una mención aparte lo ameritan los contratos sobre obras públicas, cuya competencia recae en el Ministerio de Obras Públicas y son regulados por el Decreto № 900 de 31 de octubre de 1996 que pone en vigor la Ley de Concesiones de Obras Públicas, el Decreto № 75 de 2 de febrero de 2004 que pone en vigor el Reglamento para Contratos de Obras Públicas y el Decreto $N^{\circ} 48$ de 28 de febrero de 1994 que pone en vigor el Reglamento para la Contratación de Trabajos de Consultoría junto a sus numerosas y sucesivas modificaciones. Sobre la materia, el capítulo V de la Ley de Compras Públicas se mantiene como norma de aplicación supletoria.

Otra mención aparte lo constituyen los contratos al amparo del Ministerio de Vivienda y Urbanismo, regulados por el Decreto N $^{\circ} 236$ de 9 de diciembre de 2002 que aprueba las Bases Generales Reglamentarias de Contratación de Obras para los Servicios de Vivienda y Urbanización, la Ley № 19.537 de 5 de diciembre de 1997 sobre Copropiedad Inmobiliaria y la Ley № 19.865 de 21 de marzo de 2003 sobre Financiamiento Urbano Compartido. 
Junto al marco regulatorio antes mencionado, la contratación pública en Chile tiene a su disposición una institucionalidad diversa con funciones y atribuciones determinadas. En primer término, la Dirección de Compras y Contratación Pública-DCCP-, organismo autónomo descentralizado de derecho administrativo vinculado al Ministerio de Hacienda y bajo "supervigilancia" de la Presidencia, que conforme el artículo 30 de la Ley de Compras Públicas está a cargo de la regulación y operación del mercado de compras públicas, así como de la gestión de las adquisiciones, el fomento de la oferta de bienes y servicios, la asesoría a los organismos del Estado y la operación o licitación de la operación de los sistemas informáticos del mercado público, creado por la Ley de Compras Públicas en su capítulo VI en sustitución de la Dirección de Aprovisionamiento del Estado -DAE- que era básicamente una entidad de gestión y ejecución contractual. Otras de las importantes funciones de la DCCP es el ejercicio de la representación o mandato de organismos públicos en procedimientos de contratación y la licitación por medio de convenios-marco, a esta última función se hará referencia más adelante.

En segundo término, debe mencionarse el Tribunal de Contratación Pública, creado por la Ley de Compras Públicas en su capítulo V como órgano jurisdiccional bajo la "superintendencia directiva, correccional y económica" de la Corte Suprema -según los términos del artículo 22 eiusdem-, con competencia para la materia contenciosa-administrativa especial sobre contratos públicos y particularmente para los trámites de impugnación de actos administrativos en procedimientos de contratación pública desde la licitación o primer acto hasta la adjudicación final.

En tercer lugar, fuera del ámbito específico de las compras públicas debe mencionarse la Contraloría General de la República, la cual conserva funciones de fiscalización y control de la actividad de la administración del Estado por medio del "examen preventivo", así como a través de inspecciones y auditorías.

\subsection{La Directiva de Contratación Pública número 11 y el fenómeno de la participación accionaria horizontal}

De igual forma, en Chile la colusión está prohibida por el artículo 3 del Decreto Legislativo 211 de 1973. En este sentido, las atribuciones de la Fiscalía Nacional Económica en materia de colusión, conforme el Decreto Legislativo 211 de 1973 son: acceso y allanamiento a recintos empresariales, incautación de documentación potencialmente útil para la investigación, vigilancia en las comunicaciones, consulta de registros de comunicaciones de empresas en investigación, entre otras.

Por su parte, la DCCP emite con carácter regular determinadas directivas, manuales y guías, contentivas de recomendaciones para las entidades públicas 
en materia de contratación. Dicha actividad de emisión de recomendaciones encuentra fundamento en el artículo 30 inciso h) de la Ley 19886 y pretende optimizar los procesos de contratación en interés de las propias entidades públicas. Estas recomendaciones constituyen manifestación de lo que se conoce como derecho referencial -softlaw-, constituido por documentos que carecen de valor normativo formal pues pretenden brindar una ayuda a los destinatarios para mejorar u homogeneizar determinados procesos como es la contratación pública en este caso, pero que en la práctica adquieren fuerza obligatoria a partir del consenso de los destinatarios en torno a la legitimación por razón de la materia en torno a la especialización de la institución emisora de tales recomendaciones ${ }^{67}$.

En este ámbito, corresponde a la Dirección de Compras y Contratación Pública, la orientación a los organismos del Estado en sus procesos de compras a proveedores privados, en razón de lo cual emite determinadas directivas con valor formalmente orientativo. En materia de colusión la DCCP ha emitido la Directiva de Contratación Pública número 11 de 29 de enero de 2009, que contiene las Instrucciones para la Prevención de la Colusión entre Oferentes, y cuyo propósito declarado incluye el apoyo a las entidades estatales en la prevención y detección de prácticas de carácter colusorio. Dicho instrumento se inscribe dentro de la práctica regional y global consistente en la emisión de guías-resumen de los principales aspectos que caracterizan y definen la colusión en compras públicas, bajo el propósito de sistematizar las tesis institucionales sobre dicho fenómeno en el ámbito del aprovisionamiento del Estado y con ello uniformar criterios jurídicos para la prevención y detección de tales prácticas ${ }^{68}$.

Una primera observación al instrumento jurídico debe recaer en su valor normativo. Por un lado, las directivas de la DCCP carecen de valor normativo desde un punto de vista estrictamente formal lo cual se evidencia a partir del propio lenguaje institucional. En el caso de la Directiva 11 se utilizan términos como "asesorar organismos públicos" y "apoyar a los organismos públicos en la detección oportuna".

Resulta igualmente de notar que la descripción de las condiciones favorables a la colusión, no alude a circunstancias asociadas a la participación accionaria

\footnotetext{
67 Consúltese Lara Arroyo (2011), pp. 161-198.

68 Estas guías con carácter de resumen siguen básicamente la misma estructura en su contenido: definición y caracteres de la colusión en compras públicas, descripción de las condiciones favorables en el mercado y un catálogo de supuestos o prácticas de colusión. La Directiva 11 sigue una estructura similar: Concepto, Ámbito de Aplicación, Características de la industria y de los productos y servicios contratados que incrementan los riesgos de colusión entre oferentes, Posibles casos de colusión entre oferentes, Manifestación de conductas colusorias; Instrucciones, recomendaciones y mejores prácticas; Herramientas del portal www.mercadopublico.cl y Ejemplos, con un checklist como anexo.
} 
horizontal. Sin duda alguna se trata de un fenómeno de reciente toma de razón por parte de la doctrina en EE.UU. y con casi nula atención en el ámbito latinoamericano, no obstante, el grado de desarrollo del mercado en sentido general y particularmente de la oferta en el mercado público, permiten sostener que las condiciones favorables a la colusión en Chile no se remitan únicamente a las clásicas e incluya el riesgo de colusión indirecta por medio de la participación accionaria horizontal ${ }^{69}$.

\section{Conclusiones}

A modo de conclusión, la presente contribución pretende destacar un aspecto de importante vocación técnica en el derecho de competencia, pero no por ello está al margen del proceso democrático en un país dado. Aún en los EE.UU., el derecho de competencia tiene un fuerte componente político, junto al inevitable e indispensable contenido de análisis económico y técnico; el devenir de la relación entre legislador, autoridades de cumplimiento de la legislación antitrust, sistema judicial y empresa privada ha discurrido en términos de acción legislativa, búsqueda empresarial de subterfugios legales y corrección interpretativa de las lagunas expuestas por el legislador, lo cual se ha manifestado desde etapa temprana como la decisión EC Knight de la Corte Suprema en 1895, que abrió un escape a fusiones y consolidaciones empresariales y que concluye parcialmente en los casos Addyston Pipe \& Steel Co. v US, 175 US 211, 1899 y Northern Securities Co. v US, 193 US 197, 1904.

Para Latinoamérica, debe añadirse que el derecho de competencia es un ámbito normativo relativamente nuevo, pero sobre todo indiferente. A la comunidad profesional del derecho en la región le es, la mayor de las veces, indiferente el control del poder de mercado y su funcionamiento eficiente por un sinnúmero de razones. Entre ellas pueden mencionarse la concentración de la titularidad de las empresas en grupos familiares cerrados, a diferencia de los EE.UU. o Europa, en los cuales, sin negar la existencia de tales grupos, la titularidad de

\footnotetext{
69 Solamente es dable encontrar una referencia muy somera e indirecta a la cuestión objeto de análisis, particularmente en la primera de las acciones de prevención, relativa a la información respecto de la industria antes de definir el proceso de abastecimiento y de diseñar las bases de licitación. En este sentido, la DCCP aconseja a las entidades públicas lo siguiente:

"Es importante que recopile información respecto de todo el rango de productos y/o servicios disponibles en el mercado que podrían satisfacer de manera más o menos equivalente las necesidades de la entidad pública contratante, como asimismo, informarse de los potenciales proveedores de los mismos". Más adelante, recomienda el instructivo: "Haga un buen estudio de mercado para identificar el máximo número posible de competidores con ofertas relevantes".

Aún sin mencionar la necesaria vigilancia de la estructura de acciones de las empresas que participan en el proceso de contratación, puede entenderse incluida dicha acción en el ámbito general de la recopilación de información con el propósito de lograr conocimiento sobre el mercado.
} 
las empresas está más diversificada entre inversionistas institucionales, personales y grandes grupos de ciudadanos de ingreso medio, por medio de un fuerte desarrollo del mercado de valores y de la banca de inversión.

Otra de las razones consiste en el poco vigor del ímpetu de emprendimiento empresarial serio, que impide la creación de una comunidad emprendedora vigilante de prácticas anticompetitivas por parte de las empresas grandes y establecidas; a diferencia de Estados Unidos y Europa, donde existe una vasta comunidad empresarial interesada en el funcionamiento competitivo de los mercados. Por último, en los Estados Unidos y Europa, la vigilancia del mercado no depende únicamente del Estado, sino de múltiples organizaciones, observatorios e instancias ciudadanas interesadas en el bienestar del consumidor. En el caso latinoamericano, el interés por el consumidor no parte del mismo sino del propio Estado, sea por una actitud paternalista de este o una actitud infantil del propio consumidor, siempre a la expectativa de la responsabilidad estatal en su bienestar. De algún modo, el principio de subsidiariedad no es muy fértil en la región.

Por último, cabe destacar entre los factores mencionados, la carencia de una masa crítica de profesionales expertos que permita formar una comunidad académica y de litigantes que hagan funcionales la también escasa y novísima institucionalidad encargada de la vigilancia y control del mercado, así como de las prácticas mencionadas.

A la par con todo esto, resulta evidente el desconocimiento por parte de las instituciones ad hoc, de la academia e incluso de la prensa, respecto del fenómeno de la participación de determinados inversionistas o familias en varias empresas que constituyen una cuota sustancial del mercado público para determinados productos y servicios, lo cual constituye una condición muy favorable para la colusión y con ello, la defraudación del interés público representado en el Estado.

Acorde con lo anterior, deben definirse dos grupos de soluciones al problema del derecho de competencia en general, de la colusión en compras públicas en particular y de la participación accionaria horizontal en específico: las de carácter legal y las de carácter integral. En el primer tipo de soluciones deben considerarse la solicitud de una fuerte asistencia de organismos internacionales para reconfigurar la norma antimonopolio, la formación de expertos y litigantes en la materia, la promoción de la investigación y publicaciones con criterio inter-disciplinar de análisis económico y legal del tema. No obstante, su eficacia radica en la adopción del segundo tipo de soluciones, las de carácter integral.

Estas deben considerar políticas de Estado encaminadas a lograr en lo posible el consenso entre gran empresa, sectores laborales y Estado en torno al funcionamiento competitivo del mercado. En cualquier caso, la colusión en compras públicas no es un asunto solo del derecho de competencia, sino que 
debe formar parte de la agenda anticorrupción en toda sociedad moderna; en razón de ello, y desde una perspectiva legal, la definición legislativa de limitaciones, exenciones, modalidades, alcance y límites, evidencia indiciaria, condiciones favorables y el seguimiento casuístico, resultan ser indispensables para la eficacia de este punto en la agenda anticorrupción.

\section{Bibliografía CitADA}

1. Alfaro Águila-Real, Jesús (2004): "La Prohibición de los Acuerdos Restrictivos de la Competencia. Una Concepción Privatística del Derecho Antimonopolio", en: Revista para el Análisis del Derecho InDret, (№ 4, vol. 4), pp. 61-82.

2. Alfaro Águila-Real, Jesús (2009): "Contra la Armonización Positiva: la Propuesta de la Comisión para Reforzar el Private Enforcement del Derecho de la Competencia", en: Revista para el Análisis del Derecho InDret (vol. 3). Disponible en: http://www.indret.com/pdf/667_es.pdf. [Visitado el 29/5/2016].

3. Álvarez Londoño, Luis Fernando (2008): "Últimas Tendencias en Derecho de la Competencia en América Latina", en: Vniversitas (num. 115), pp. 248-262.

4. Araya Jasma, Fernando (2012): "Determinación del Mercado Relevante en la Colusión entre Oferentes en Licitaciones: ¿ Hacia un Acuerdo Ilícito por su Objeto Anticompetitivo? Corte Suprema, 11 de enero de 2012, rol 68742011", en: Revista Chilena de Derecho Privado, (№ 18), pp. 223-241.

5. Araya Jasma, Fernando (2014): "Sobre los Distintos tipos de Boicot Colectivo y la Colusión en Concursos. Corte Suprema, 23 de diciembre de 2013, rol 2666-2013", en: Revista Chilena de Derecho Privado, (núm. 22), pp. 314-354.

6. Areeda, Phillip Elias, Hovenkamp, Herbert, Elhauge, Einer Richard (2000): Antitrust Law: An Analysis of Antitrust Principles and Their Application (London, Wolters Kluwer Law \& Business).

7. Averitt, Neil, Lande, Robert (1997): "Consumer Sovereignty: A Unified Theory of Antitrust and Consumer Protection Law", en: Antitrust Law Journal ( $\mathrm{N}^{\circ} 2$, vol. 65), pp. 713-756.

8. Averitt, Neil, Lande, Robert (2007): "Using the "Consumer Choice" Approach to Antitrust Law", en: Antitrust Law Journal (vol. 74), pp. 175-264.

9. AzAr, José et al. (2016): "Ultimate Ownership and Bank Competition", en: Social Sciences Research Network. Disponible en: http://papers.ssrn.com/ sol3/papers.cfm?abstract_id=2710252. [Visitado el 29/5/2016].

10. BAKer, Jonathan (2006): "Competition Policy as a Political Bargain", en: Antitrust Law Journal (No 2, vol. 73), pp. 483-530. 
11. BAKER, Jonathan (2016): "Overlapping Financial Investor Ownership. Market Power and Antitrust Enforcement: My Qualified Agreement with Professor Elhauge", en: Harvard Law Review Forum (№ 5, vol. 129), pp. 212-232.

12. Cabanellas de las Cuevas, Guillermo (2005): "Derecho Antimonopólico y de Defensa de la Competencia" (Buenos Aires, Heliasta).

13. COASE, Ronald (2009): The Nature of the Firm (Boston, McMillan Education).

14. DatTA, Devangshu (2015): "Investing in Peer Stocks", en: Business Standard (agosto 2), p. 4.

15. Davidson, Ken (2015): "Elhauge, Read the Wrong Way?", en: Linkedin Pulse Forum. Disponible en: https://www.linkedin.com/pulse/elhauge-read-wrongway-ken-davidson. [Visitado el 29/5/2016].

16. Elhauge, Einer (2016): "Horizontal Shareholding", en: Harvard Law Review (No 5, vol. 129), pp. 1.267-1.317.

17. Elhauge, Einer; Geradin, Damien (2011): Global Antitrust Law and Economics (London, Foundation Press-Thomson Reuters).

18. Gong, Ting, Zhou, Na (2015): "Corruption and Marketization: Formal and Informal Rules in Chinese Public Procurement", en: Regulation \& Governance (No 1, vol. 9), pp. 63-76.

19. Kaplow, Louis, Shapiro, Carl (2007): "Antitrust", en: John M. Olin Center for Law, Economics and Business, Harvard Law School (Discussion Paper 01/2007). Disponible en: http://www.law.harvard.edu/programs/olin_center/ papers/pdf/Kaplow_695.pdf:. [Visitado el 29/5/2016].

20. Kovacic, William, Shapiro, Carl (2000): "Antitrust Policy: A Century of Economic and Legal Thinking", en: Journal of Economic Perspectives ( $N^{\circ} 1$, vol. 14), pp. 43-60.

21. Lara Arroyo, José Luis (2010): "La Regulación Administrativa en Materia Económica y sus Nuevas Manifestaciones. La Irrupción del Denominado Soft-Law", en: ArsBoni et Aequi. Revista Jurídica de la Universidad Bernardo O’Higgins, (№ 2, vol. 7), pp. 161-198.

22. Lara Arroyo, José Luis (2011): "La responsabilidad del Estado por su actividad jurídica bilateral: El caso de las licitaciones en materia de Contrato de Suministro y Prestación de Servicios bajo la Ley No 19.886", en: Revista lusPublicum, (No 27, vol. 13,), pp. 51-71.

23. LIANOS, loannis (2008): "Collusion in Vertical Relations under Article 81 EC", en: Common Market Law Review ( $\mathrm{N}^{\circ}$ 4, vol. 45), pp. 1.027-1.077.

24. Martínez, Juan Francisco et al (2011): "Sobre los Determinantes de la Colusión en las Compras Públicas: el Caso de Chile", en: Revista de la Facultad de Derecho PUCP, (No 66), pp. 385-417. 
25. O’Brien, Daniel, SALOP, Steven (2000): "Competitive Effect of Partial Ownership: Financial Interest and Corporate Control", en: Antitrust Law Journal (vol. 67), pp. 559-614.

26. Organización Mundial de la Propiedad Intelectual (1996): "Disposiciones Tipos sobre la Protección contra la Competencia Desleal", en: Wipo Web Page. Disponible en: http://www.wipo.int/edocs/pubdocs/es/intproperty/832/ wipo_pub_832.pdf. [Visitado el 29/5/2016].

27. Organización para la Cooperación y el Desarrollo Económico (2012): "Combate a la Colusión en los Procesos de Contratación Pública en México, Informe Analítico del Secretariado sobre el Cumplimiento de la Legislación, Regulaciones y Prácticas de la CFE con las Mejores Prácticas de la OCDE", en: OECD Web Page. Disponible en: http://www.oecd.org/ daf/competition/CombateColusi\%C3\%B3nContrataci\%C3\%B3nP\%C3\% BAblica-M\%C3\%A9xico-InformeCFE-2015.pdf. [Visitado el 29/5/2016].

28. Ramírez Duarte, Olga Lucía (2012): "Mecanismos para Combatir la Colusión en Licitaciones: Efectos de las Decisiones Sancionatorias sobre el Proceso Licitatorio en Colombia" en: Repositorio Colegio Mayor de Nuestra Señora del Rosario. Disponible en: http://repository.urosario.edu.co/bitstream/handle/10336/3591/53166440-2012.pdf?sequence=1 [visitado el 29/05/2016].

29. Sistema Económico Latinoamericano (2015): “Las Compras Públicas como Herramienta de Desarrollo en América Latina y el Caribe. Documento SP/ RRSSCPALC/DT 2-15", en: Servicio Nacional de Contratación Pública del Ecuador. Disponible en: http://www.sela.org/media/268508/las-compras-publicas-como-herramienta-de-desarrollo-en-alc.pdf. [Visitado el 29/5/2016].

30. TAPIA, Javier (2009): "Carácter Anticompetitivo de los Acuerdos Restrictivos de la Competencia", en: Social Sciences Research Network. Disponible en: http://papers.ssrn.com/sol3/papers.cfm?abstract_id=1440695. [Visitado el 29/5/2016].

31. Velandia, Mauricio (2011): Derecho de la Competencia y del Consumo (Bogotá, Universidad Externado de Colombia).

32. Volosin, Natalia (2015): "Datos Abiertos, Corrupción y Compras Públicas", en: Iniciativa Latinoamericana por los Datos Abiertos, Open Data. Disponible en: http://idatosabiertos.org/wp-content/uploads/2015/10/5.-Corrupcion-ycompras-publicas-Volosin1.pdf [visitado el 29/5/2016].

33. WeishaAr, Stefan (2013): Cartels, Competition and Public Procurement. Law and Economics Approaches to Bid Rigging (Cheltenham, Edward Elgar Publishing).

34. Werden, Gregory (2014): "The Relevant Market: Possible and Productive", en: Antitrust Law Journal Online (Abril, 2014). Disponible en: http://www. 
americanbar.org/content/dam/aba/publishing/antitrust_law_journal/at_alj_ werden.authcheckdam.pdf [visitado el 29/5/2016].

35. WITKER, Jorge (2000): Derecho de la competencia en América, Canadá, Chile, EE.UU. y México (México, D.F., Fondo de Cultura Económica).

\section{NORMAS JURÍDICAS CITADAS}

1. Acuerdo sobre Contratación Pública, anexo al Protocolo por el que se modifica el Acuerdo sobre Contratación Pública, de 30 de marzo de 2012.

2. Decisión del Consejo Andino de Ministros de Relaciones Exteriores 668 de 13 de junio de 2007, Plan Andino de Lucha contra la Corrupción.

3. Decreto $N^{\circ} 1.687$ de 14 de mayo de 2010, por el cual se modifica el Decreto № 3.523 de 2009. Diario Oficial de la República de Colombia, 47709.

4. Decreto $N^{\circ} 2.153$ de 31 de diciembre de 1992, por el cual se reestructura la Superintendencia de Industria y Comercio y se dictan otras disposiciones. Diario Oficial de la República de Colombia, 40704.

5. Decreto № 236 de 9 de diciembre de 2002 que aprueba las Bases Generales Reglamentarias de Contratación de Obras para los Servicios de Vivienda y Urbanización.

6. Decreto $N^{\circ} 3.523$ de 15 de septiembre de 2009, por el cual se modifica la estructura de la Superintendencia de Industria y Comercio y se determinan las funciones de sus dependencias. Diario Oficial de la República de Colombia, 47473.

7. Decreto No 48 de 28 de febrero de 1994 que pone en vigor el Reglamento para la Contratación de Trabajos de Consultoría.

8. Decreto $N^{\circ} 75$ de 2 de febrero de 2004 que pone en vigor el Reglamento para Contratos de Obras Públicas.

9. Decreto $N^{\circ} 900$ de 31 de octubre de 1996 que pone en vigor la Ley de Concesiones de Obras Públicas.

10. Decreto Ejecutivo № 1.152 de 7 de mayo de 2012 de la Presidencia de la República del Ecuador, Reglamento de la Ley Orgánica de Regulación y Control del Poder de Mercado.

11. Decreto Legislativo № 211 de 1973, Ley de Defensa de la Libre Competencia, Refundido.

12. Directiva de Contratación Pública número 11 de 29 de enero de 2009.

13. Ley $N^{\circ} 1.340$ de 24 de julio de 2009, por medio de la cual se dictan normas en materia de protección de la competencia. Diario Oficial de la República de Colombia, 47420. 
14. Ley $N^{\circ} 15$ de 4 de julio de 2007, de Defensa de la Competencia. Boletín Oficial del Estado Español, número 159.

15. Ley $\mathrm{N}^{\circ} 155$ de 14 de diciembre de 1959, por la cual se dictan algunas disposiciones sobre prácticas comerciales restrictivas. Diario Oficial de la República de Colombia, 30138.

16. Ley $N^{\circ} 18.575$ de 12 de noviembre de 1986, Ley Orgánica de Bases Generales de la Administración del Estado.

17. Ley $\mathrm{N}^{\circ} 19.537$ de 5 de diciembre de 1997, Ley sobre Copropiedad Inmobiliaria.

18. Ley No 19.653 de 3 de diciembre de 1999, Ley sobre Probidad Administrativa aplicable a los Órganos de la Administración del Estado.

19. Ley № 19.865 de 21 de marzo de 2003, Ley sobre Financiamiento Urbano Compartido.

20. Ley $N^{\circ} 19.880$ de 22 de mayo de 2003, Ley que establece las Bases de los Procedimientos Administrativos que rigen los Actos de los Órganos de la Administración del Estado.

21. Ley $N^{\circ} 19.886$ de 11 de julio de 2003, Ley de Bases sobre Contratos Administrativos de Suministro y Prestación de Servicios.

22. Ley № 73 de 12 de junio de 2002, Ley Orgánica de la Contraloría General del Estado de la República del Ecuador. Registro Oficial 595.

23. Ley s/n de 13 de abril de 2004, Ley Orgánica de la Procuraduría General del Estado de la República del Ecuador. Registro Oficial 312.

24. Ley s/n de 13 de octubre de 2011, Ley Orgánica de Regulación y Control del Poder de Mercado. Registro Oficial 555.

25. Ley s/n de 4 de agosto de 2008, Ley Orgánica del Sistema Nacional de Contratación Pública de la República del Ecuador. Registro Oficial 395.

26. Ley s/n de 7 de agosto de 2013, Ley Orgánica de la Función de Transparencia y Control Social de la República del Ecuador. Registro Oficial 53.

27. Pub. L. 98-369, 1984. Competition in Contracting Act. Julio 18, 1984.

28. Public Law 98-544 USA. Local Government Antitrust Act. Octubre 24 de 1984.

29. Reglamento (CE) 772 de 2004, relativo a la aplicación del apartado 3 del artículo 81 del Tratado a determinadas categorías de acuerdos de transferencia de tecnología. Diario Oficial de la Comunidad Europea. Abril 27 de 2004.

30. Reglamento (UE) 1217 de 2010, relativo a la aplicación del artículo 101 apartado 3, del Tratado de Funcionamiento de la Unión Europea a determinadas categorías de acuerdos de investigación y desarrollo. Diario Oficial de la Unión Europea. Diciembre 18 de 2010. 
31. Reglamento (UE) 267 de 2010. Relativo a la aplicación del artículo 101, apartado 3, del Tratado de Funcionamiento de la Unión Europea a determinadas categorías de acuerdos, decisiones y prácticas concertadas en el sector de los seguros. Diario Oficial de la Unión Europea. Marzo 30 de 2010.

32. Reglamento (UE) 461 de 2010, relativo a la aplicación del artículo 101, apartado 3, del Tratado de Funcionamiento de la Unión Europea a determinadas categorías de acuerdos verticales y prácticas concertadas en el sector de los vehículos de motor. Diario Oficial de la Unión Europea. Mayo 28 de 2010.

33. Reglamento 17 de 1962, Normas de aplicación y de procedimiento de los artículos 81 y 82 del Tratado CE. Diario de la Comunidad Económica Europea, Febrero 21 de 1962.

34. Reglamento CE 1 de 2003, relativo a la aplicación de las normas sobre competencia previstas en los artículos 81 y 82 del Tratado. Diario Oficial de la Unión Europea. Enero 4 de 2003.

35. Reglamento CE 139 de 2004, sobre el control de concentraciones entre empresas. Diario Oficial de la Comunidad Europea. Enero 29 de 2004.

36. Reglamento CEE 4064 de 1989, sobre el control de operaciones de concentración de empresas. Diario Oficial de la Comunidad Económica Europea. Septiembre 21 de 1990.

37. Reglamento UE 1218 de 2010, relativo a la aplicación del artículo 101 apartado 3, del Tratado de Funcionamiento de la Unión Europea a determinadas categorías de acuerdos de especialización. Diario Oficial de la Unión Europea. Diciembre 18 de 2010.

38. Reglamento UE 330 de 2010, relativo a la aplicación del artículo 101 apartado 3, del Tratado de Funcionamiento de la Unión Europea a determinadas categorías de acuerdos verticales y prácticas concertadas. Diario Oficial de la Unión Europea. Abril 23 de 2010.

39. Resolución de la Asamblea General de las Naciones Unidas 35/63 de 5 de diciembre de 1980, sobre prácticas comerciales restrictivas.

40. Tratado Constitutivo de la Comunidad Económica Europea. 1957.

41. Tratado de la Unión Europea y Tratado de Funcionamiento de la Unión Europea. 2012.

42. Tratado de Lisboa por el que se modifican el Tratado de la Unión Europea y el Tratado constitutivo de la Comunidad Europea. 2007.

43. United States Federal Acquisition Regulation, 48 CFR 1. 


\section{JURISPRUDENCIA Y CASUÍSTICA}

1. Addyston Pipe \& Steel Co. v US, 175 US 211 (1899).

2. Arizona v. Maricopa County Medical Society, 457 U.S. 332 (1982).

3. Blomkest Fertilizer, Inc. v. Postash Corp. of Saskatchewan, Inc.203 F.3d 1028, 8th Cir. (2000).

4. Broadcast Music v. Columbia Broadcasting System, 441 U.S. 1 (1979).

5. Brooke Group Ltd. v. Brown \& Williamson Tobacco Corp., 509 U.S. 209 (1993).

6. California v ARC America Corp., 490 US 93, 104-105 (1989).

7. City of Columbia v Omni Outdoor Advertising, 499 US 365, 372-73 (1991).

8. Comisión Europea. Decisión 2001/354/CEE, Deutsche Post AG (Comisionado Mario Monti, Marzo 20 de 2001).

9. Comisión Europea. Decisión 84/380/CEE, SyntheticFibres (Comisionado Andriessen; Julio 4 de 1984).

10. Comisión Europea. Decisión 85/77/CEE, Uniform Eurocheques (Comisionado LeonBrittan, Diciembre 10 de 1984).

11. Comisión Europea. Decisión 88/138/CEE, EurofixBauco (Comisionado Peter Sutherland, Diciembre 22 de 1987).

12. Comisión Europea. Decisión 91/297, Soda-Ash-Solvay/ICI (Comisionado LeonBrittan, Diciembre 19 de 1990).

13. Comisión Europea. Decisión 92/163/CEE, TetraPak II (Comisionado Presidente Cruz Vilaça, Julio 24 de 1991).

14. Community Communications Co. v City of Boulder, 455 US 40, 50-54 (1982).

15. Consejo de Estado de la República de Colombia. Sala de lo Contencioso Administrativo. Sección 3ra., Subsección C. Proceso 54549 (Consejero Ponente: Santofimio Gamboa, Septiembre 4 de 2015).

16. Corte Europea de Justicia. Caso 32/65. República Italiana v Comisión. 1966.

17. Corte Europea de Justicia. Caso 56/65. Société TechniqueMiniere v Maschinenbau Ulm. 1966.

18. Corte Europea de Justicia. Caso 58/64. Etablissements Consten SA \& GrundigVerkaufs-Gmbh v Comisión. 1966.

19. Corte Europea de Justicia. Sala 1 ra. Asunto 48/69, ICI Ltd v Comisión Dyestuffs- (Magistrado Lecourt, Julio 14 de 1972).

20. Corte Europea de Justicia. Sala 3ra. Ampliada. Asunto T-228/97, Irish Sugar PLC v Comisión (Magistrado Ponente Lenaerts, Octubre 7 de 1999). 
21. Corte Europea de Justicia. Sala 3ra. Ampliada. Asunto T-28/93, Compagnie Maritime Belge Transps SA v Comisión (Magistrado Ponente Briët, Octubre 8 de 1996).

22. Corte Europea de Justicia. Sala 5ta. Ampliada. Asunto T-340/03, France Télécom v Comisión (Magistrado Ponente Vilaras, Enero 30 de 2007).

23. Corte Europea de Justicia. Sala 5ta. Decisión C-62/86, AkzoChemie BV v Comisión (Juez Joliet, Julio 3 de 1991).

24. Corte Europea de Justicia. Sala 6ta. Asunto T-43/92, Dunlop Slazenger International Ltd v Comisión (Magistrado Mancini, Julio 8 de 1999).

25. Corte Europea de Justicia. Sala Plena. Asunto 40/73, SuikerUnie (Magistrado Presidente Lecourt, Diciembre 16 de 1975).

26. Corte Europea de Justicia. Sala Plena. Asuntos 89, 104, 114, 116, 117, 125 al 129/85 (Presidente Lord Mackenzie Stuart, Septiembre 27 de 1988).

27. Corte Suprema de Justicia de Colombia. Sala Plena. Sentencia C-415/1994 (Magistrado Ponente Cifuentes Muñoz, Septiembre 22 de 1994).

28. Credit Suisse Securities v Billing, 551 US 264, 275 (2007).

29. Dedication \& Everlating Love to Animals v Humane Society, 50 F. 3d 710, 9th Circ. (1995)

30. Eastman Kodak Co. v. Image Technical Servs., Inc., 504 U.S. 451 (1992).

31. Fisher v City of Berkeley, 475 US 260 (1986).

32. Flood v Kuhn, 407 US 258 (1972).

33. FTC v. Motion Picture Advertising Svc. Co., Inc. 344 U.S. 392 (1953).

34. Gordon v. New York Stock Exchange, Inc. 422 U.S. 659 (1975).

35. Group Life \& Health Ins. Co. v Royal Drug Co., 440 US 205, 231 (1979).

36. Hoover v Ronwin, 466 US 558, 567-69 (1984).

37. Illinois Tool Works Inc. v. Independent Ink, Inc., 547 U.S. 28 (2006).

38. In Re High Fructose Corn Syrup Antitrust Litigation, 295 F.3d 651, 654, 7th Circ. (2002).

39. Jefferson Parish Hosp. Dist. v. Hyde 466 U.S. 2 (1984).

40. Leegin Creative Leathers Products, Inc v PSKS, Inc., 127 S Ct 2705 (2007).

41. Maryland \& Va. Milk Producers Association v United States, 362 US 458 (1960).

42. McLain v Real Estate Board of New Orleans, 444 US 232 (1980).

43. National GerimedicalHosp\& Gerontology Center v Blue Cross, 452 US 378, 389 (1981). 
44. National Petroleum Refiners Association v FTC, 482 F.2d 672, 673-78, DC Circ (1973).

45. NCAA v University of Oklahoma Board of Regents, 468 US 85, 109 (1984).

46. Northern Securities Co. v United States, 193 US 197 (1904).

47. Palmer v. BRG of Georgia, Inc. 498 U.S. 46 (1990).

48. Silver v NYSE, 373 US 341, 357 (1963).

49. Standard Fashion Co. v. Magrane-Houston Co. 258 U.S. 346 (1922).

50. Standard Oil Co. v. United States, 337 U.S. 293 (1949).

51. State Oil v Kahn, 522 US 3 (1997).

52. Summit Health v Pinhas, 500 US 322 (1991).

53. Superintendencia de Industria y Comercio. Resolución № 1.055 de 2009. Caso Intersystem, Buitrago Camargo y Vega Cruz. Enero 19 de 2009.

54. Tampa Electric Co. v. Nashville Coal Co., 365 U.S. 320 (1961).

55. Texaco Inc. v. Dagher, 547 U.S. 1 (2006).

56. Theatre Enterprises Inc. v Paramount Film Distributing Corp., 346 US 537 (1954).

57. Tribunal de Justicia de las Comunidades Europeas. Sala Plena. Asunto T-201/04, Microsoft v Comisión (Magistrado Presidente Vesterdorf, Septiembre 17 de 2007).

58. United States v Socony-Vacuum Oil Co., 310 US 150 (1940).

59. United States v Trenton Potteries Co., 273 US 392 (1927).

60. United States v. AMR Corp., 335 F.3d 1109, 10th Cir. (2003).

61. United States v. E. C. Knight Co., 156 U.S. 1 (1895).

62. United States v. E. I. du Pont de Nemours \& Co. 351 U.S. 377 (1956).

63. United States v. Microsoft Corporation 253 F.3d 34 (D.C. Cir. 2001).

64. United States v Aluminium Co. of America-Alcoa, 148 F.2d 416, 2nd Circ. (1945).

65. United States v E.I. Du Pont de Nemours \& Co., 351 US 377, 391 (1956).

66. United States v Griffith, 334 US 100 (1948). 